\title{
QUALIDADE DA ÁGUA E ABASTECIMENTO NA AMAZÔNIA: o exemplo da bacia hidrográfica do rio Caeté
}

\author{
Prof $^{\mathrm{a}}$. Dr ${ }^{\mathrm{a}}$. Adryane Gorayeb \\ Pós-Graduação em Geografia da Universidade Federal do Ceará \\ Campus do Pici, Bloco 911 - CEP 60.455-760 - Fortaleza (CE), Brasil \\ Telfax: (55 85) 3366.9855 ou 3366.9864 - adryanegorayeb@yahoo.com.br \\ Prof $^{\mathrm{a}}$. Dr ${ }^{\mathrm{a}}$. Magda Adelaide Lombardo \\ lombardo@rc.unesp.br \\ Prof $^{\mathrm{a}}$. Dr ${ }^{\mathrm{a}}$. Luci Cajueiro Carneiro Pereira \\ cajueiro@ufpa.br
}

\begin{abstract}
RESUMO
As análises da qualidade da água e das condições do abastecimento público nas bacias hidrográficas amazônicas revelam-se como ferramentas essenciais para o desenvolvimento sustentável da região, uma vez que previne conflitos entre os usuários, permitindo o desenvolvimento de atividades compatíveis sem causar danos na saúde pública local. As análises dos resultados demonstraram que diversos setores da bacia do Caeté encontram-se fora do padrão estabelecido pela legislação brasileira, em especial os mananciais públicos das cidades de Bragança e Santa Luzia do Pará, fazendose necessário um monitoramento rigoroso com medidas de despoluição das águas, uma vez que a baixa qualidade da água afeta a biodiversidade local e a saúde das populações consumidoras.
\end{abstract}

Palavras-chave: Amazônia Oriental, bacia hidrográfica, análise da qualidade da água.

\begin{abstract}
The analysis of the quality the water and the conditions of the public supplies available in the hydrographic basins of the Amazon is an essential prerequisite for the region's social and environmental development. An overview of the results indicates that the water quality in many parts of the Caeté basin - in particular the municipal supplies of the cities of Bragança and Santa Luzia do Pará - is below the standards set by the Brazilian legislation. This emphasizes the need for the establishment of stricter monitoring procedures and the implementation of measures for the reduction of pollution levels, considering the implications of such low water quality for local biodiversity and the health of local consumers.
\end{abstract}

Key words: Eastern Amazon, hydrographic basin, analysis of water quality.

\section{RESUMEN}

Los análisis de la calidad del agua y de las condiciones de abastecimiento público en las cuencas hidrográficas amazónicas se han revelado herramientas esenciales para el desarrollo sostenible de la región, una vez que previene conflictos entre los usuarios, permitiendo el desarrollo de actividades compatibles sin dañar la salud pública local. Los análisis de los resultados demuestran que distintos sectores de la cuenca de Caeté se encuentran fuera del estándar establecido por la legislación brasileña, en especial los manantiales públicos de las ciudades de Bragança y Santa Luzia de Pará, se haciendo necesario una monitorización rigurosa con medidas de descontaminación de las aguas, una vez que la baja calidad del agua afecta la biodiversidad local y la salud de las poblaciones consumidoras.

Palabras clave: Amazônia Oriental, cuenca hidrográfica, análisis de la calidade del água.

\section{INTRODUÇÃO}

As bacias hidrográficas da região amazônica foram alvo de políticas públicas nacionais que incentivaram a ocupação do solo e a exploração dos recursos naturais desde a década de 1970 e que repercutem até os dias atuais (AB'SABER, 2004). Os planos e projetos de governo, em geral, agiram a partir do pressuposto de que a Amazônia seria um macro-sistema homogêneo de florestas, rios e igarapés e estimularam a substituição dos sistemas naturais por atividades produtivas degradantes, como agricultura de exportação, pecuária extensiva e exploração mineral de grande escala.

Nas últimas décadas, enormes massas vegetais, que incluem madeiras nobres, foram queimadas impiedosamente. De 1500 a 1970, ou seja, em 470 anos, apenas 2\% de toda a Floresta Amazônica havia sido destruída. Porém, dados do Instituto Nacional de Pesquisas Espaciais (INPE) revelam 
que em apenas 30 anos (1970 a 2000) foram devastados 14\% da floresta, consequência de um modelo econômico que vai de encontro aos propósitos de conservação e preservação ambiental (LOUREIRO, 2001).

Concomitante à intensa exploração, o incentivo público à ocupação humana na região determinou um crescimento urbano sem precedentes. As estatísticas do Instituto Brasileiro de Geografia e Estatística (IBGE) demonstram que em 1970 a população urbana da região amazônica representava apenas 3,5\% da população total. Já em 1980 esse índice cresceu para 44,6\%, em 1996 para 61\% e em 2000 foi demonstrado que 69,7\% da população viviam em cidades (BECKER, 1995, 1998, 2004). Tal ritmo galopante e tal proporção fundamentaram a concepção da Floresta como urbanizada.

Neste contexto, o nordeste Paraense, região onde está inserida a Bacia Hidrográfica do Rio Caeté, abriga a maior densidade demográfica do estado do Pará e possui investimentos intensivos em agropecuária, além de ser caracterizado como o local de colonização mais antiga da Amazônia, datada do século XVII (ROSÁRIO, 2000). Este fato histórico contribuiu para uma intensa exploração dos recursos naturais, através do extrativismo vegetal (madeira em tora, lenha e carvão) e da agropecuária, com o cultivo de culturas de subsistência, frutíferas, malva, pimenta-do-reino, cocodendê e criação de gado bovino e bubalino (BAENA; FALESI; DUTRA, 1998).

Como principais problemas ambientais da bacia pode-se relacionar o desmatamento, a prática ilegal da mineração e a poluição hídrica provinda das sedes municipais de Santa Luzia do Pará e de Bragança e de setores da zona rural, através da utilização de agrotóxicos, fertilizantes, acúmulo de lixo, falta de saneamento básico e etc. (GUIMARÃES et al., 2009; GORAYEB; LOMBARDO; PEREIRA, 2009; SILVA; PEREIRA; COSTA, 2009). Além de causar problemas ao meio natural, essas atividades também acarretam prejuízos diretos para as comunidades ribeirinhas e para as populações urbanas, considerando-se o consumo de água de baixa qualidade e a disseminação de doenças de veiculação hídrica.

Desse modo, o presente estudo teve como objetivos analisar i) a qualidade da água dos mananciais públicos de Bragança (rio Chumucuí, afluente da margem esquerda do baixo curso do rio Caeté) e Santa Luzia do Pará (poços tubulares), ii) dois pontos de amostragem no alto curso do rio Caeté e um no médio curso e iii) dois pontos de amostragem em dois afluentes do rio Caeté, sendo o rio Curizinho (afluente da margem direita do médio curso do rio Caeté) e o rio Cereja (afluente da margem esquerda do baixo curso do rio Caeté), como forma de identificar o estado atual dos ambientes fluviais da bacia e do abastecimento público nas cidades.

\section{METODOLOGIA}

\section{Área de Estudo}

A bacia hidrográfica do rio Caeté está inserida nas seguintes coordenadas geográficas: $\mathrm{N}-0^{\circ}$

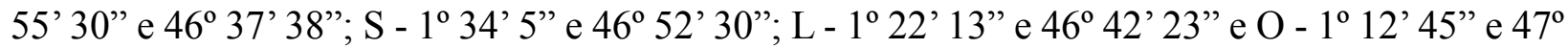
7' 22" (Figura 1).

A bacia do Caeté possui uma área de $2.195 \mathrm{~km} 2$ e extensão do rio principal de $149 \mathrm{~km}$ (GORAYEB, 2008), das nascentes (município de Bonito) à foz (municípios de Bragança e Augusto Corrêa), desaguando na baía Caeté-Urumajó, que é dominada por macromarés semidiurnas (SOUZA FILHO, 1995).

Formada predominantemente por sedimentos tércio-quaternários do Grupo Barreiras e depósitos areno-argilosos do Quaternário, a geomorfologia da bacia é representada pelo Planalto Costeiro e pela Planície Litorânea, com altitudes máximas na cota de $80 \mathrm{~m}$ e relevo marcado por terrenos planos e suavemente ondulados (BRASIL, 1973). O clima da região é tipicamente tropical chuvoso, com temperatura máxima de $30,8^{\circ} \mathrm{C}$, mínima de $21,2^{\circ} \mathrm{C}$ e média de $26^{\circ} \mathrm{C}$ (OLIVEIRA JUNIOR et al., 1999). As chuvas não se distribuem igualmente ao longo do ano, concentrando-se nos meses de janeiro a junho (80\%), o que implica em grandes excedentes hídricos e cheias dos rios (PARÁ, 2004). 
Em relação à cobertura vegetal, a região apresentava predominantemente Vegetação Florestal Perenifólia, Vegetação Hidrófila e Floresta Amazônica de Terra Firme, mas atualmente encontra-se profundamente modificada, prevalecendo a Vegetação Florestal Secundária, os pastos e as lavouras permanentes e temporárias (PARÁ, 2004). Apresenta associações de Latossolos Amarelos, Neossolos Quartzarênicos e Argissolos Vermelho-Amarelo (PARÁ, 2004). De modo geral, esses solos apresentam pré-disposição natural a processos erosivos e são utilizados para o cultivo de pastagem, mandioca, milho, arroz, feijão caupi, coco-da-baía e coco-dendê (FERREIRA; OLIVEIRA, 2001).

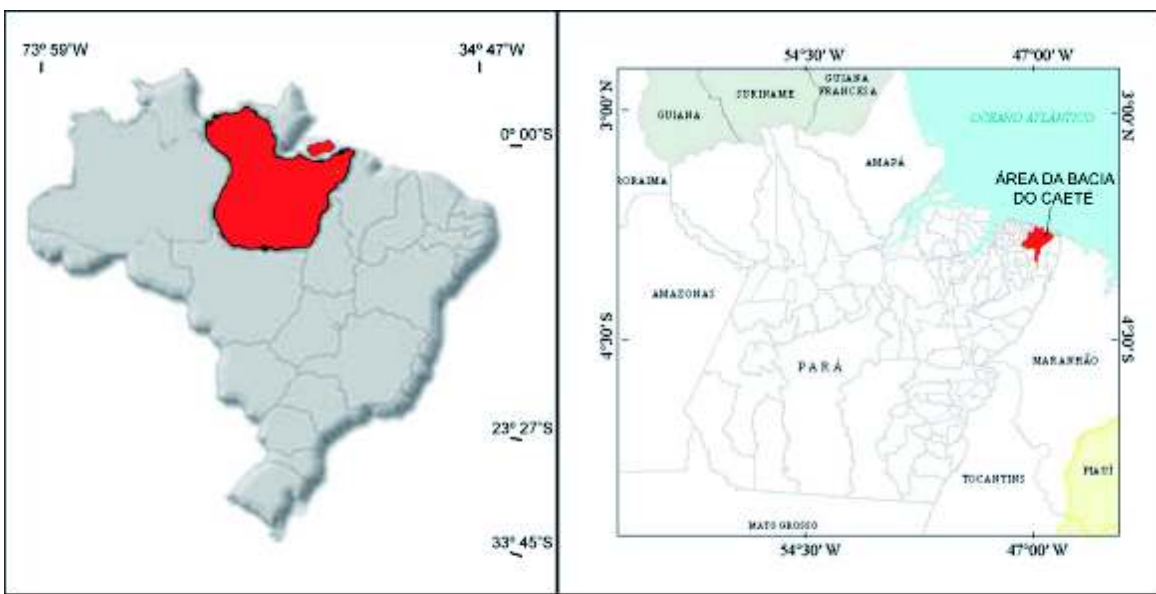

BACIA HIDROGRÁFICA DO RIO CAETÉ

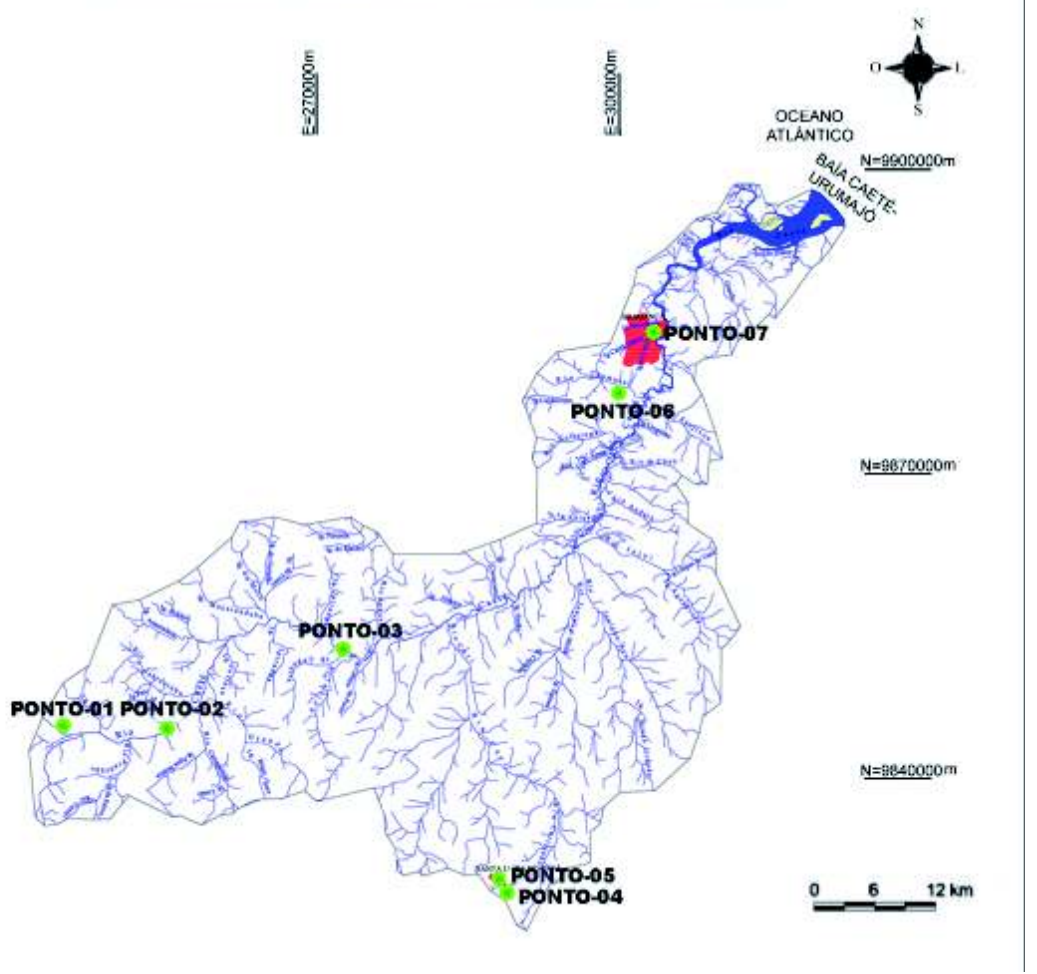

Figura 1 - Localização geográfica da Bacia Hidrográfica do Rio Caeté com os pontos de coleta de água.

Na região estuarina ocorrem principalmente a Vegetação de Mangue (95\% da área) (SOUZA FILHO; EL-ROBRINI, 1996), prevalecendo os Gleissolos Sálicos e Tiomórficos parcialmente submersos, orgânicos, salinos e extremamente ácidos (SANTOS, 1999).

A bacia do Caeté drena parcialmente o território de sete municípios localizados no Nordeste do Pará: Bonito, Ourém, Santa Luzia do Pará, Capanema, Tracuateua, Bragança e Augusto Corrêa (GORAYEB, 2008), com uma população total estimada em 285.028 habitantes (IBGE, 2000). 
Porém, influencia diretamente na drenagem de apenas duas sedes municipais: Santa Luzia do Pará (médio curso, rio Curizinho, afluente da margem direita) e Bragança (baixo curso, leito principal do rio Caeté) (GORAYEB, 2008).

Foram criadas quatro Unidades de Conservação nos municípios drenados pelo rio Caeté, todas pertencentes ao grupo de Uso Sustentável, sendo duas em Bragança, uma em Augusto Corrêa e uma em Tracuateua, identificadas respectivamente como: 1) Área de Proteção e Preservação Ambiental Permanente Ilha do Canela, 2,3 km2, Lei Municipal no. 3.280 de 29/10/1997; 2) Reserva Extrativista Marinha de Caeté-Taperaçu, 278,6 km2, Decreto Federal de 20/05/2005; 3) Área de Proteção Ambiental da Costa de Urumajó, 306,18 km2, Lei Municipal nº 1.352 de 05/08/1998 e 4) Reserva Extrativa Marinha de Tracuateua, 189,9 km2, Decreto Federal de 20/05/2005. Porém, somente a Reserva Extrativista Marinha Caeté-Taperaçu está inserida dentro da área da bacia, em parte da região do baixo curso do rio Caeté (GORAYEB, 2008).

Para a análise da qualidade hídrica foram definidos e georreferenciados (GPS Garmin 72) em campo, sete pontos de amostragem em seções de rios e nos poços tubulares que abastecem a cidade de Santa Luzia do Pará (Figura 1), levando-se em consideração os usos diversos e a influência dos núcleos habitacionais (Tabela 1).

\begin{tabular}{|c|c|c|c|}
\hline $\begin{array}{l}\text { Pontos de } \\
\text { Coleta }\end{array}$ & Água Superficial & Coordenadas Geográficas & Município \\
\hline P-01 & Rio Caeté - Nascentes Principais (alto curso) & $1^{\circ} 23^{\prime} 37.2^{\prime \prime} ; 47^{\circ} 16^{\prime} 45.7^{\prime \prime}$ & Bonito \\
\hline P-02 & Rio Caeté - Arraial do Caeté (alto curso) & $1^{\circ} 23,37.5 " ; 47^{\circ} 11^{\prime} 14.2 "$ & Ourém \\
\hline P-03 & Rio Caeté - Tentugal (médio curso) & $1^{\circ} 19^{\prime} 16^{\prime \prime} ; 47^{\circ} 2^{\prime} 4.2^{\prime \prime}$ & Santa Luzia do Pará \\
\hline P-05 & $\begin{array}{l}\text { Rio Curizinho - Sede Municipal (médio } \\
\text { curso) }\end{array}$ & $1^{\circ} 31^{\prime} 40.9^{\prime \prime} ; 46^{\circ} 53^{\prime} 42.5 \prime$ & Santa Luzia do Pará \\
\hline P-06 & $\begin{array}{l}\text { Rio Chumucuí - Ponto de Captação da } \\
\text { COSANPA* (médio curso) }\end{array}$ & $1^{\circ} 5^{\prime} 50.8^{\prime \prime} ; 46^{\circ} 47^{\prime} 33.6^{\prime \prime}$ & Bragança \\
\hline P-07 & $\begin{array}{c}\text { Rio Cereja - Sede Municipal (baixo curso) } \\
\text { Água Subterrânea }\end{array}$ & $1^{\circ} 2 ’ 59 ” ; 46^{\circ} 45^{\prime} 7.7^{\prime \prime}$ & Bragança \\
\hline P-04 & $\begin{array}{l}\text { Poços Tubulares - Ponto de Captação da } \\
\text { COSANPA (médio curso) }\end{array}$ & $1^{\circ} 32^{\prime} 30.6^{\prime \prime} ; 46^{\circ} 53^{\prime} 51.5^{\prime \prime}$ & Santa Luzia do Pará \\
\hline
\end{tabular}

* Companhia de Saneamento do Pará

\section{Materiais e métodos}

Foram realizadas sete coletas de água, no período de fevereiro de 2006 a fevereiro de 2007, com frequência bimestral. As campanhas contemplaram o período chuvoso (primeiro semestre) e seco (segundo semestre) da região nordeste do Pará.

Para fins de organização, foram utilizadas planilhas de campo e listagem de materiais e os procedimentos de preparação e preservação das amostras seguiram às normas da ABNT (1987).

Para cada amostra foram analisados os parâmetros físicos, químicos, hidrobiológicos e microbiológicos, cujas metodologias são apresentadas na Tabela II. As análises foram realizadas no Laboratório de Controle de Resíduos da Universidade Federal do Pará (UFPA) e no Laboratório de Oceanografia Costeira e Estuarina da UFPA - Campus de Bragança.

Na inexistência de enquadramento dos corpos hídricos superficiais do estado do Pará, os padrões de referência utilizados foram os estabelecidos pela Resolução CONAMA n. 357 de 17 de março de 2005 (CONAMA, 2005) para as águas doces de Classe 2, as quais se destinam: a) ao abastecimento para consumo humano, após tratamento convencional; b) à proteção das comunidades aquáticas; c) à recreação de contato primário, natação, esqui-aquático e mergulho; d) à irrigação de hortaliças, plantas frutíferas, parques, jardins, campos de esporte e lazer, com os quais o público possa vir a ter contato direto, à aquicultura e à atividade de pesca. Assim, conforme o CONAMA (2005), as águas destinadas ao abastecimento humano têm que ser submetidas ao tratamento convencional antes de serem consumidas. Este tratamento supõe quatro operações distintas: floculação, decantação, filtração e desinfecção. 
Tabela 2 - Parâmetros analisados e respectivas metodologias analíticas referenciadas.

\begin{tabular}{|c|c|c|c|}
\hline Parâmetro & Metodologia & Materiais & Referência \\
\hline \multicolumn{4}{|l|}{ Hidrobiológicos } \\
\hline Clorofila-a & Espectrofotométrico & Espectrofotômetro & $\begin{array}{l}\text { Strickland e Parsons } \\
\text { (1972) }\end{array}$ \\
\hline \multicolumn{4}{|l|}{ Físicos } \\
\hline Cor aparente (mg Pt/L) & Colorimétrico & Colorímetro Hach DR/890 & \multirow{5}{*}{$\begin{array}{c}\text { APHA; AWWA; WEF } \\
\text { (1998) }\end{array}$} \\
\hline Turbidez (UNT) & Turbidimétrico & Turbidímetro Hach 2100P & \\
\hline \multicolumn{3}{|l|}{ Químicos } & \\
\hline $\begin{array}{l}\text { Demanda bioquímica de } \\
\text { oxigênio - DBO }\left(\mathrm{mgO}_{2} / \mathrm{L}\right)\end{array}$ & Incubação $\left(20^{\circ} \mathrm{C}, 5\right.$ dias $)$ & $\begin{array}{l}\text { Incubadora de DBO, modelo } \\
\text { LICIT. }\end{array}$ & \\
\hline Amônia livre (mg/L) & $\begin{array}{l}\text { Espectrofotometria Absorção } \\
\text { Molecular - Nesslerização } \\
\text { direta }\end{array}$ & \multirow[b]{4}{*}{$\begin{array}{l}\text { Espectrofotômetro, HACH } \\
2010\end{array}$} & \\
\hline Nitrato $(\mathrm{mg} / \mathrm{L})$ & Reação de Griess & & \multirow{3}{*}{$\begin{array}{l}\text { Strickland e Parsons } \\
\text { (1972); Grasshoff; } \\
\text { Emrhardt; Kremling, } \\
\text { (1983) }\end{array}$} \\
\hline Nitrito (mg/L) & & & \\
\hline Fosfato (mg/L) & Redução com ácido ascórbico & & \\
\hline $\mathrm{Ph}$ & Phamétrico & $\begin{array}{c}\text { pHmetro PHS - 3B, Labmeter } \\
\text { Model } \mathrm{PH} 2\end{array}$ & Medição analítica \\
\hline $\begin{array}{l}\text { Oxigênio dissolvido - OD } \\
(\mathrm{mg} / \mathrm{L})\end{array}$ & Analítica & Multianalisador & Em campo \\
\hline \multirow[b]{2}{*}{ Ferro dissolvido (mg/L) } & $\begin{array}{l}\text { Redução com Orto- } \\
\text { fenantrolina }^{1}\end{array}$ & $\begin{array}{l}\text { Espectrofotômetro HACH } \\
2010\end{array}$ & $\begin{array}{c}\text { APHA; AWWA; WEF } \\
\text { (1998) }\end{array}$ \\
\hline & Analítica $^{2}$ & $\begin{array}{l}\text { Hardness \& Iron HI } 93741 \\
\text { Hanna Instruments }\end{array}$ & Medição analítica \\
\hline \multicolumn{4}{|l|}{ Microbiológicos } \\
\hline \multirow[t]{2}{*}{$\begin{array}{l}\text { Coliformes Termotolerantes } \\
(\mathrm{NMP} / 100 \mathrm{~mL})\end{array}$} & Método Colilert ${ }^{1}$ & $\begin{array}{l}\text { Substrato definido meio } \\
\text { mínimo onpg - mug, } \\
\text { composto por dois ou mais } \\
\text { substratos específicos para } \\
\text { detecção via enzimática }\end{array}$ & \multirow[t]{2}{*}{$\begin{array}{c}\text { APHA; AWWA; WEF } \\
\text { (1998) }\end{array}$} \\
\hline & Tubos múltiplos - Meio $\mathrm{A}_{1}^{2}$ & $\begin{array}{l}\text { Meios de cultura } \\
\text { Autoclave } \\
\text { Estufa }\end{array}$ & \\
\hline
\end{tabular}

1 Análises realizadas nas amostras de FEV/2006, ABR/2006, JUN/2006, AGO/2006 e OUT/2006 no Laboratório de Controle de Resíduos da UFPA.

2 Análises realizadas nas amostras de DEZ/2006 e FEV/2007 no Laboratório de Oceanografia Costeira e Estuarina da UFPA - Campus de Bragança.

A Resolução CONAMA(2005) não estabelece valor máximo e mínimo para o fosfato, porém tal indicador foi utilizado com o intuito de complementar as análises da qualidade da água superficial.

Foram utilizados os critérios estabelecidos pela Portaria do Ministério da Saúde (MS) n. 518 de 25 de março de 2004 (BRASIL, 2004) para a análise da qualidade da água subterrânea de Santa Luzia do Pará, por estabelecer o padrão de potabilidade da água para o consumo humano.

Considera-se que a Portaria MS n. 518 é aplicável para a análise da água consumida na sede de Santa Luzia do Pará, uma vez que o município não dispõe de Estação de Tratamento de Água 
(ETA), ou seja, a água bruta captada é canalizada e segue diretamente para as residências, sem qualquer tratamento prévio.

O ponto de amostragem P-06, rio Chumucuí, também foi analisado conforme os parâmetros estabelecidos pela Portaria n. 518 (BRASIL, 2004), haja vista servir como fonte de captação de água do município de Bragança.

A variável fosfato também não possui padrão estabelecido pela Portaria MS n. 518, porém é utilizada no decorrer do trabalho para complementar as análises da qualidade da água.

\section{RESULTADOS E DISCUSSÃO}

\section{Condições do abastecimento público de água nas sedes municipais}

Em Bragança, a água é captada diretamente do leito do rio Chumucuí, afluente da margem esquerda do rio Caeté, e a cidade de Santa Luzia do Pará é abastecida por mananciais subterrâneos, através de um sistema de poços tubulares. A COSANPA é a concessionária que gerencia o abastecimento de água nas duas cidades, incluindo a ETA de Bragança.

A fonte de captação de água de Santa Luzia do Pará é, conforme relatos, uma antiga nascente fluvial cujo rio foi assoreado. O manancial público possui uma bateria de 28 poços artesianos em funcionamento, além de 17 desativados. Todos os poços têm a profundidade padrão de $6 \mathrm{~m}$ e o município não dispõe de ETA.

Conforme a Resolução CONAMA n. 357 de 17 de março de 2005, as águas destinadas ao abastecimento humano têm que ser submetidas ao tratamento convencional antes de serem consumidas. Esse tratamento, realizado na ETA de Bragança, possui quatro operações distintas: floculação, decantação, filtração e desinfecção.

Na ETA de Bragança, a floculação ocorre a partir da adição de sulfato de alumínio. Em seguida, os flocos de materiais em suspensão se depositam no fundo do decantador, pela ação da gravidade (COSANPA, 2007). Após esta etapa, realiza-se a filtração da água, que é considerado o processo mais importante no tratamento. Finalmente, a desinfecção é feita através da aplicação de cloro gasoso, com o intuito de produzir um meio isento de microorganismos patogênicos (COSANPA, 2007).

De forma complementar, são realizados os procedimentos de correção do $\mathrm{pH}$, com o intuito de diminuir a acidez da água que prejudica o encanamento, adicionando-se cal hidratado, e de fluoretação, acrescentando-se fluoreto de sódio no final do processo.

A adição de sais de flúor na água de abastecimento público foi instituída pelo Decreto n. 76.872 de 22 de dezembro de 1975 (BRASIL, 1975) e previne cáries dentais somente em indivíduos que tenham até 14 anos, diminuindo o grau de eficácia conforme o aumento progressivo da idade (BRASIL, 2006). No entanto, o excesso de flúor no organismo pode causar uma falha no desenvolvimento do esmalte do dente chamada fluorose, caracterizada por manchas, cavidades e alterações morfológicas na superfície dentária (FEZA, 2004).

Por esse motivo, os sistemas de abastecimento público devem obedecer a alguns requisitos mínimos para que o processo de fluoretação responda positivamente na saúde pública, como: i) abastecimento regular e contínuo da água, ii) atendimento aos padrões de potabilidade; iii) sistema de operação e manutenção adequados, iv) controle regular da água distribuída e v) realização de levantamento dos dentes cariados, perdidos e obturados (índice cpo) nas crianças, após 10 - 15 anos de aplicação de flúor na água (BRASIL, 2006).

Contudo, sabe-se que a ETA de Bragança não atende a nenhum dos requisitos fundamentais para a obtenção dos resultados positivos na prevenção de incidência de cáries, instituídos pelo Ministério da Saúde, podendo acarretar prejuízos à saúde bucal de crianças e adolescentes, como demonstrado no trabalho de Vasconcellos (1982). 
O abastecimento de água de uma cidade deve trazer, fundamentalmente, benefícios à população residente e isso está intimamente relacionado à preservação da qualidade hídrica. Porém, o município de Santa Luzia do Pará não possui ETA e em Bragança as condições da estação são extremamente precárias, com problemas operacionais constantes (Figura 2).

Em termos ambientais, sabe-se que os efluentes provenientes da lavagem dos filtros e o lodo presente nos decantadores da ETA de Bragança, contendo resíduos de sulfato de alumínio, são despejados no terreno da própria concessionária e fluem em direção ao mesmo corpo hídrico onde se capta água.

A toxicidade potencial desses resíduos para plantas, seres humanos e organismos aquáticos depende de diversos fatores, como: i) as características da água bruta, ii) os produtos químicos utilizados e possíveis contaminantes contidos nesses produtos, iii) as reações químicas ocorridas durante o processo, iv) a forma de remoção do lodo, v) o tempo de retenção do lodo nos decantadores e vi) as características físicas, químicas e biológicas do curso d'água (CORDEIRO; CAMPOS, 1999).

\section{Análise da qualidade da água do manancial público de Bragança (rio Chumucuí)}

No rio Chumucuí, os parâmetros cor aparente e turbidez são influenciados predominantemente por fatores naturais, como as condições do solo e o aporte de matéria orgânica constantemente despejada no corpo hídrico.

A cor é um indicativo da presença de substâncias, geralmente orgânicas, dissolvidas no corpo hídrico (LUCAS, 2007). A Figura 3 apresenta os valores de cor aparente do rio Chumucuí (P-06) e as análises revelaram que o único período que atendeu ao padrão estabelecido pela Portaria MS n. $518(15 \mathrm{uH})$ foi o de abril/2006, com $4 \mathrm{uH}$. O valor máximo foi observado em fevereiro/2007, com $250 \mathrm{uH}$.

Quanto à turbidez, a Figura 4 demonstra que durante todo o período o rio Chumucuí permaneceu dentro do padrão estabelecido pela legislação (5 UNT), com exceção do período de dezembro/2006, quando foi obtido o valor de 7,5 UNT.

No tratamento das águas para abastecimento foi destacada a influência da presença de ferro na etapa de coagulação e floculação. As águas que contêm ferro são reconhecidas por apresentarem cor elevada (CETESB, 2007), característica encontrada no rio Chumucuí. A Figura 5 apresenta os valores de ferro dissolvido do rio Chumucuí e as análises revelaram que, no período chuvoso (primeiro semestre), os valores não atenderam ao padrão estabelecido pela Portaria MS n. 518 (0,3 $\mathrm{mg} / \mathrm{L})$ : abril/2006 (0,6 mg/L), junho/2006 (1,6 mg/L) e fevereiro/2007 (0,4 mg/L).

Em relação ao oxigênio dissolvido, a Figura 6 demonstra que somente em abril/2006 o valor de OD esteve no limite de atendimento ao padrão da Resolução n. 357 ( $\geq 5 \mathrm{mg} / \mathrm{L}$ ), quando foi observado $5,1 \mathrm{mg} / \mathrm{L}$.

Quanto aos valores da demanda bioquímica de oxigênio (DBO), a Figura 7 revela que o rio Chumucuí encontra-se dentro do padrão estabelecido pelo CONAMA $(2005)(\leq 5 \mathrm{mg} / \mathrm{LO} 2)$, podendose destacar o mês de outubro/2006, que apresentou o maior valor (4,5 mg/L O2).

Em relação aos valores de coliformes termotolerantes (Figura 8), as análises revelaram que o rio Chumucuí encontra-se fora dos padrões estabelecidos pela Portaria MS n.518 (ausência em 100 $\mathrm{mL})$, com o menor valor de coliformes atribuído para o mês de fevereiro/2006 (2 NMP/100mL) e o maior valor em fevereiro/2007 (1100 NMP/100mL). Porém, vale destacar que a água bruta passa pelo processo de tratamento convencional antes da população consumir e, apesar do aumento progressivo na quantidade de coliformes termotolerantes encontrada no corpo hídrico, deve-se realizar análises com maior periodicidade para se estabelecer um diagnóstico definitivo sobre o manancial público. 


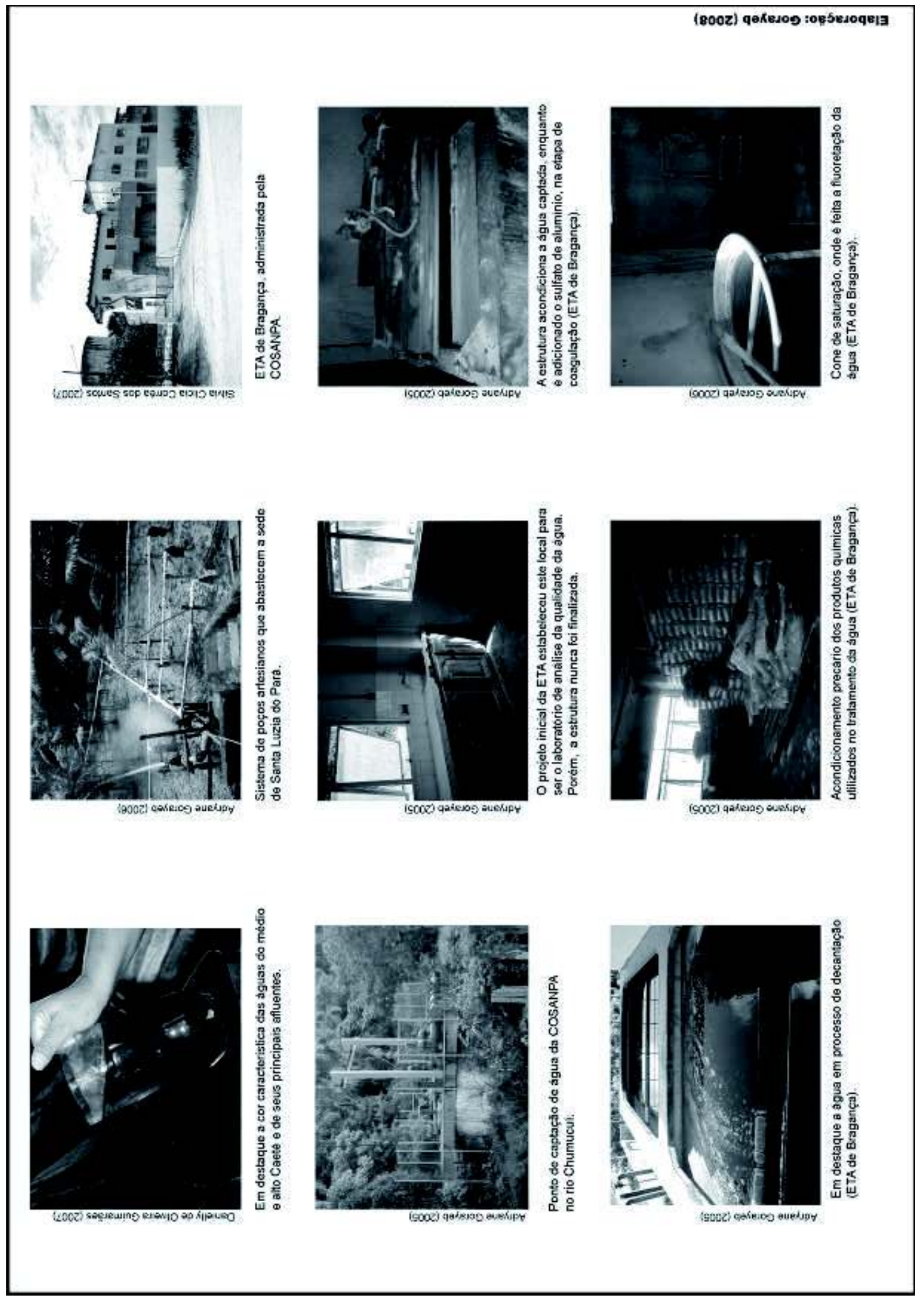

Figura 2 - Condições de infraestrutura e qualidade da água submetida ao tratamento convencional na ETA de Bragança. 


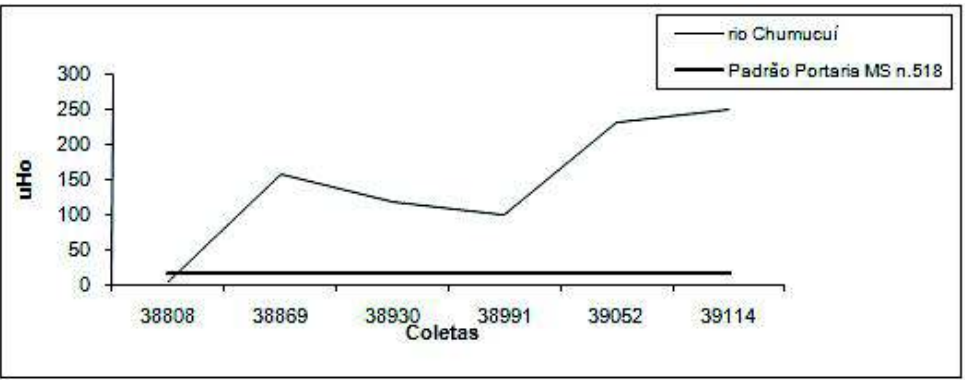

Figura 3 - Valores de cor aparente no rio Chumucuí

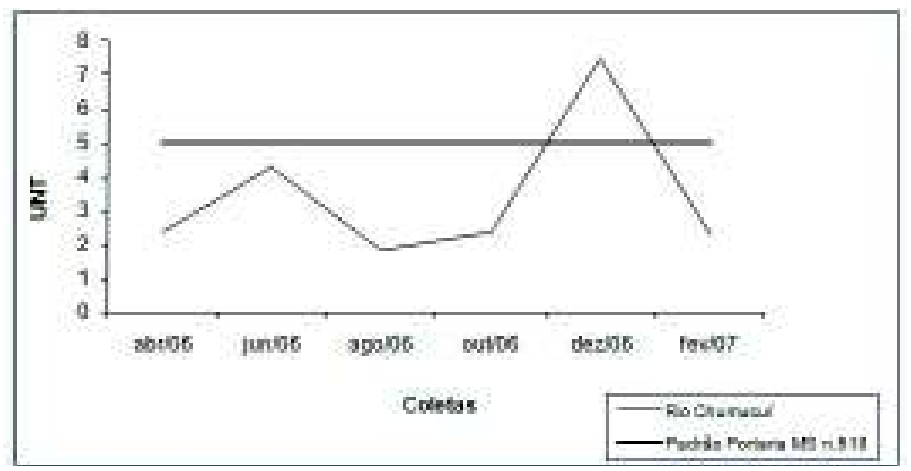

Figura 4 - Valores de turbidez no rio Chumucuí.

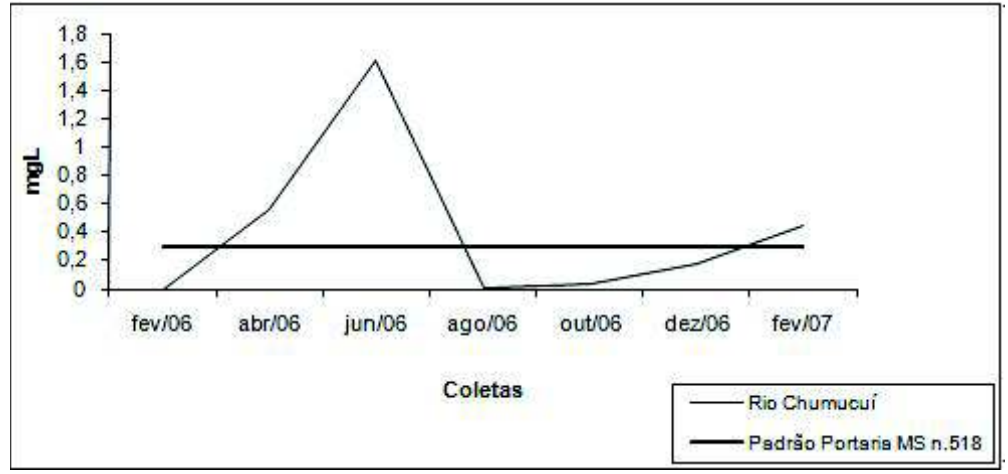

Figura 5 - Valores de ferro dissolvido no rio Chumucuí.

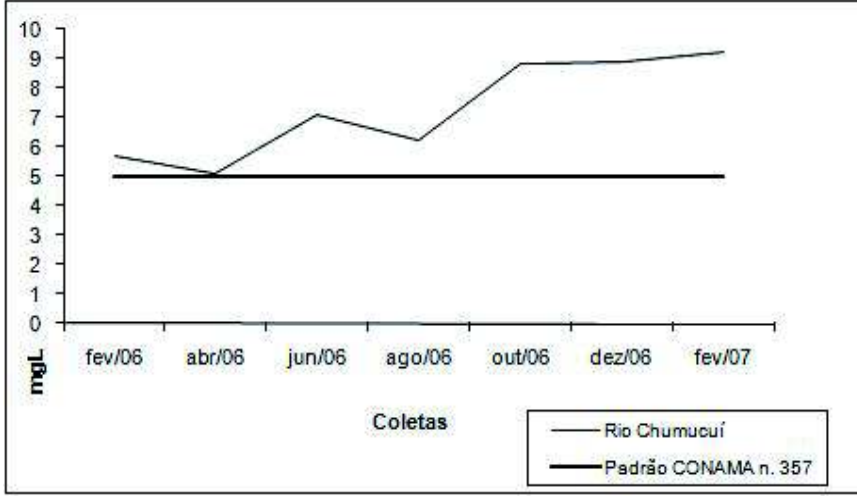

Figura 6 - Valores de OD no rio Chumucuí. 


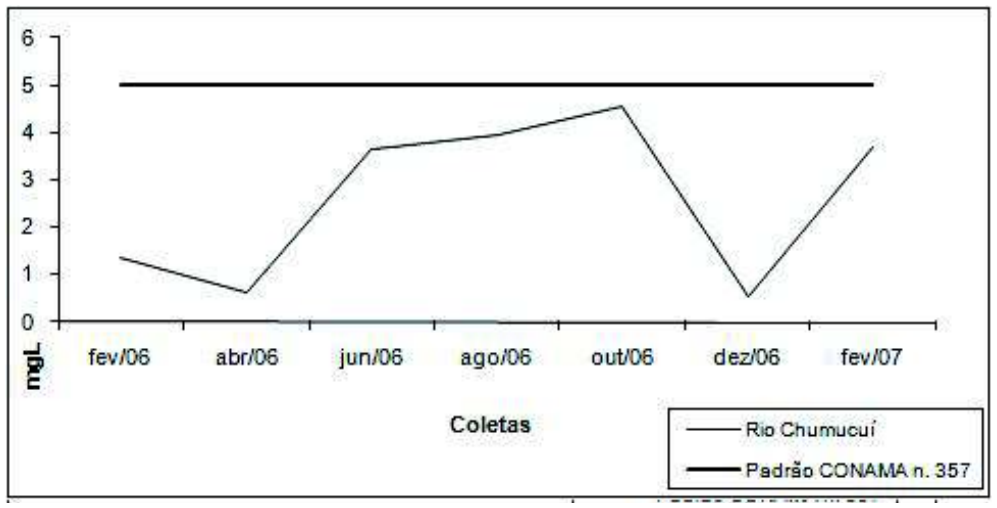

Figura 7 - Valores de DBO no rio Chumucuí.

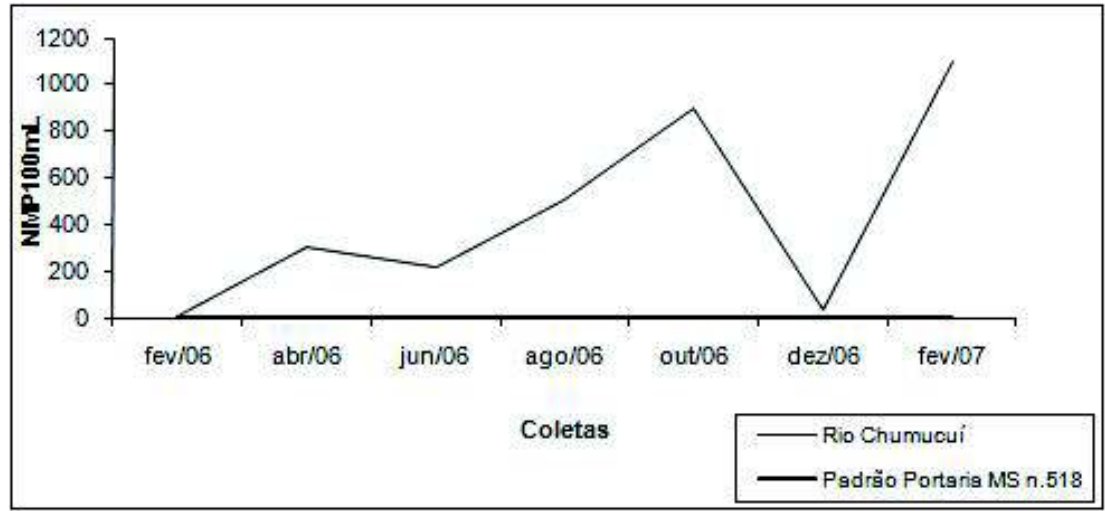

Figura 8 - Valores de coliformes termotolerantes no rio Chumucuí

O rio Chumucuí mostrou-se com índices elevados de clorofila-a (Figura 9) durante o período chuvoso, em especial nos meses de abril/2006 (31,8 $\mu \mathrm{g} / \mathrm{L})$ e junho/2006 (34,2 $\mu \mathrm{g} / \mathrm{L})$, com valores acima do máximo estabelecido pelo CONAMA $(2005)(10 \mu \mathrm{g} / \mathrm{L})$.

Todos os períodos atenderam ao padrão estabelecido pelo Ministério da Saúde para a amônia livre, tendo em vista que o percentual máximo permitido é $1,5 \mathrm{mg} / \mathrm{L}$. Os valores de nitrato e nitrito estão relacionados com a eutrofização dos corpos hídricos e revelaram-se dentro do padrão da Portaria MS n. 518: nitrato $<10 \mathrm{mg} / \mathrm{L}$ e nitrito $<1 \mathrm{mg} / \mathrm{L}$. As Figuras 10, 11 e 12 demonstram os valores durante o período estudado.

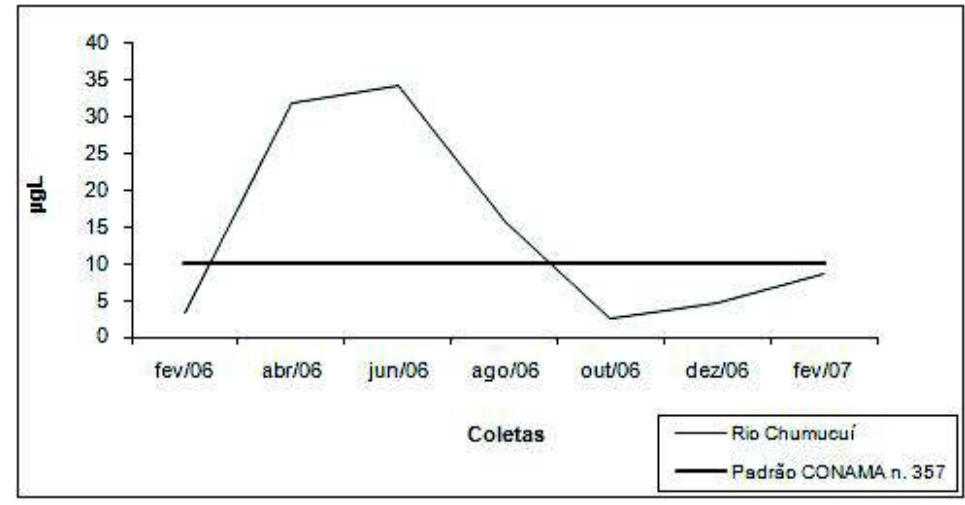

Figura 9 - Valores de clorofila-a no rio Chumucuí. 


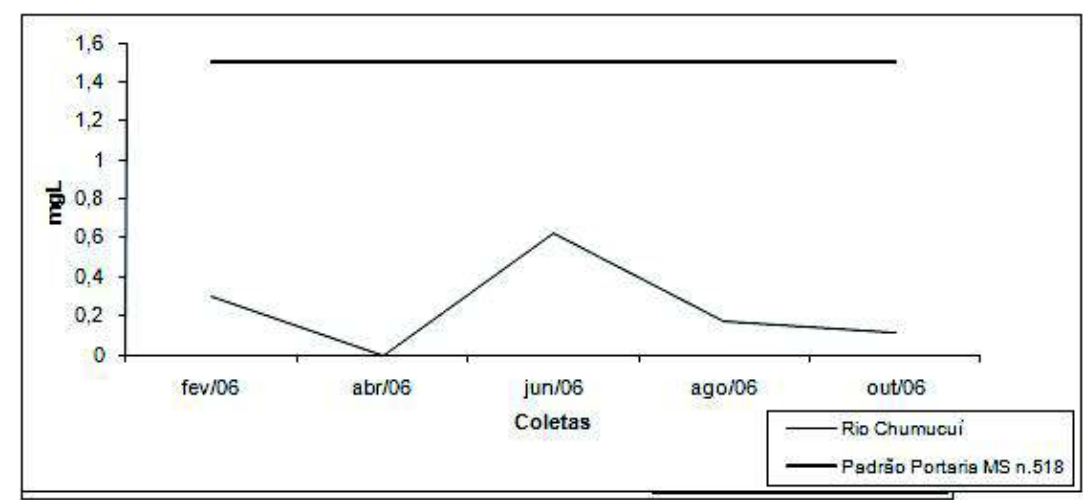

Figura 10 - Valores de amônia livre no rio Chumucuí.

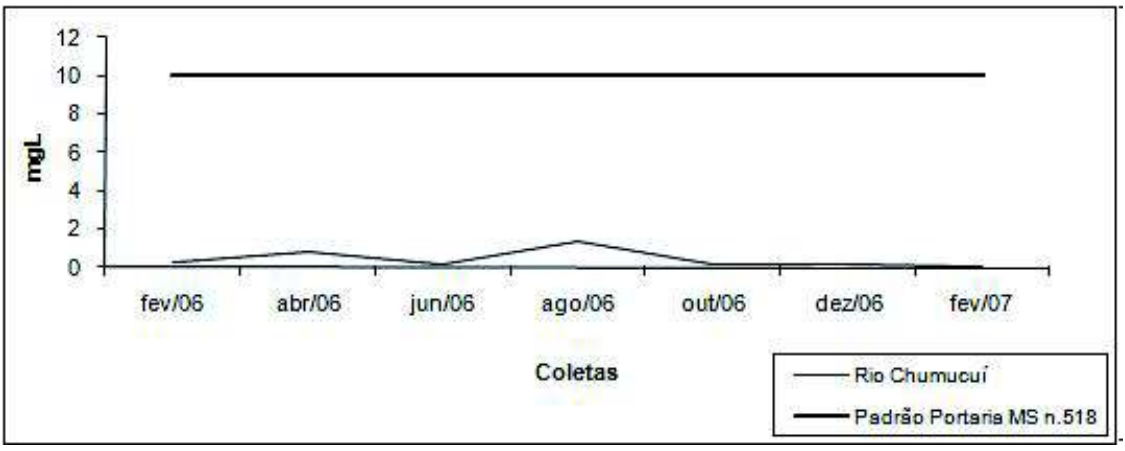

Figura 11 - Valores de nitrato no rio Chumucuí.

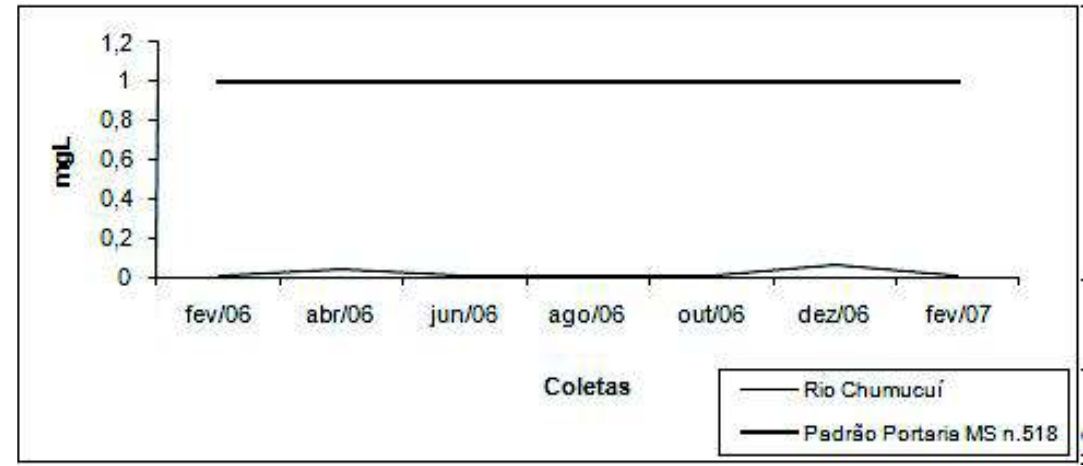

Figura 12 - Valores de nitrito no rio Chumucuí.

Todos os valores de fosfato tenderam a zero, com o maior valor encontrado em abril/2006 (0,16 mg/L), conforme a Figura 13.

$\mathrm{O} \mathrm{pH}$ permaneceu ácido praticamente todo o período entre fevereiro/2006 e fevereiro/2007 (Figura 14), seguindo a tendência dos corpos hídricos regionais (CPRM, 1998a; CPRM, 1998b; HORBE et al. 2005; SANTOS et al., 2006; SILVA et al., 2008). Tal característica pode estar associada à natureza dos solos predominantes na região, classificados como ácidos a extremamente ácidos (LOPES; RODRIGUES; OLIVEIRA JUNIOR, 1999; SANTOS et al., 1999; FERREIRA; BOTELHO, 1999; OLIVEIRA JUNIOR et al., 1999; BAENA; FALESI; DUTRA, 1998). Sabese que o pH é muito influenciado pela quantidade de matéria orgânica a ser decomposta, isto é, quanto maior a quantidade de matéria orgânica disponível, menor o $\mathrm{pH}$, uma vez que para haver decomposição de materiais são produzidos muitas substâncias ácidas como, por exemplo, o ácido húmico (FARIAS, 2006). 


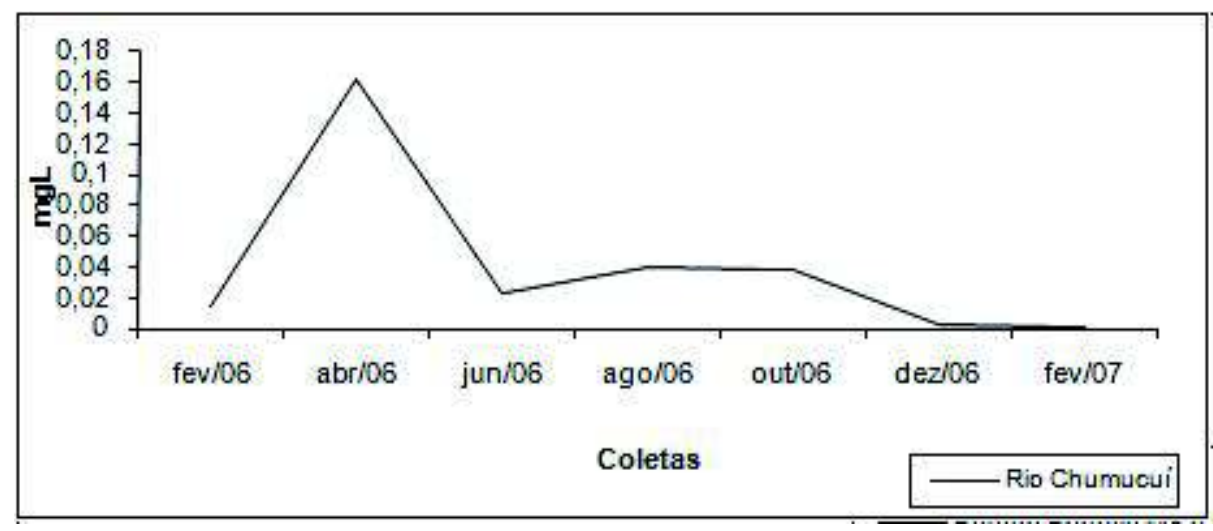

Figura 13 - Valores de fosfato no rio Chumucuí.

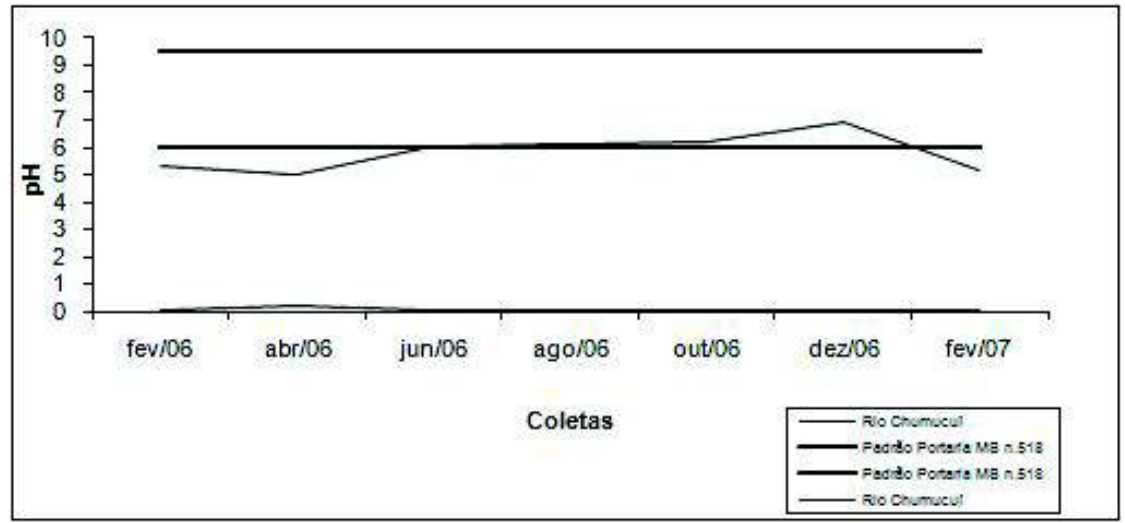

Figura 14 - Valores de pH no rio Chumucuí.

Conforme Maier (1987), os valores de $\mathrm{pH}$ dos rios brasileiros têm tendência de ácido a neutro, sendo que alguns rios da Amazônia brasileira possuem $\mathrm{pH}$ próximo de 3, valor muito baixo para suportar diversas formas de vida.

Os maiores problemas identificados no manancial público de Bragança estão relacionados 1) à alteração dos valores de turbidez e cor, que dificultam o processo de tratamento da água; 2) à acidez hídrica, que pode prejudicar a estrutura física dos encanamentos, 3) ao teor de ferro dissolvido, que em certos períodos do ano atribuem sabor e coloração diferenciada à água; e, de modo mais grave, 4) aos níveis de coliformes termotolerantes e clorofila-a encontrados no corpo hídrico.

Miranda et al. (2009), em estudos realizados no rio Tapajós (Pará) durante o período chuvoso, identificaram relação entre a variação de $\mathrm{pH}$ e os valores de $\mathrm{OD}$, indicando que o nível de OD na água influencia diretamente no desenvolvimento das espécies formadoras de ácidos fracos, que reduzem o pH. Ainda em relação ao OD, Miranda et al. (2009) obtiveram a média de 5,8 mg/L, com valor mínimo de $4,5 \mathrm{mg} / \mathrm{L}$, relacionando o valor baixo à proximidade de matadouros e lixões às margens do rio pesquisado.

Análises reveladas por CPRM (1998a) registraram para o rio Chumucuí valores de cor aparente, turbidez, série de nitrogênios (amônia livre, nitrato, nitrito), fosfato, ferro dissolvido e concentrações de OD dentro dos padrões recomendados pelo Ministério da Saúde e pela Resolução n. 357 para as águas de classe 2. Os únicos parâmetros que estiveram fora dos valores máximos permitidos foram o pH que revelou-se ácido (4,7); a DBO, com 7,0 mg/L e os coliformes termotolerantes, cuja concentração foi de $1.500 \mathrm{NMP} / 100 \mathrm{~mL}$.

Todavia, o mesmo estudo apresentou dados referentes à qualidade da água após o tratamento convencional realizado pela COSANPA, com amostras coletadas na rede de distribuição, demonstrando que todos os elementos analisados (cor, turbidez, série de nitrogênios e coliformes termotolerantes) estão dentro do padrão estabelecido pelo Ministério da Saúde, com exceção do pH que esteve abaixo do valor mínimo recomendo pela legislação (CPRM, 1998a). 
Assim sendo, o melhor método de assegurar água adequada para o consumo humano consiste nas diversas formas de preservação hídrica, evitando-se contaminações de dejetos animais e humanos, os quais podem conter grande variedade de bactérias, vírus, protozoários e helmintos (D’ÁGUILA et al., 2000).

Porém, vale considerar que para se estabelecer um diagnóstico adequado para o manancial público de Bragança, devem-se realizar análises mais detalhadas do corpo hídrico, com maior periodicidade e diversidade dos elementos estudados. Ademais, é essencial um monitoramento constante da qualidade da água do reservatório (in natura) e da água submetida ao tratamento convencional, que é consumida pela população urbana de Bragança.

\section{Análise da qualidade da água do manancial público de Santa Luzia do Pará (sistema de poços} tubulares)

A Figura 15 apresenta os valores de cor aparente do ponto de captação de Santa Luzia do Pará. As análises revelaram que a água subterrânea atendeu ao padrão estabelecido pela Portaria MS n. 518 (15 uH), porém os valores máximos foram observados em abril/2006 e outubro/2006, alcançando valores de $10 \mathrm{uH}$.

Quanto à turbidez, a Figura 16 demonstra que em dezembro/2006 o ponto não permaneceu dentro do padrão do Ministério da Saúde (5 UNT), apresentando o valor de 6,1 UNT.

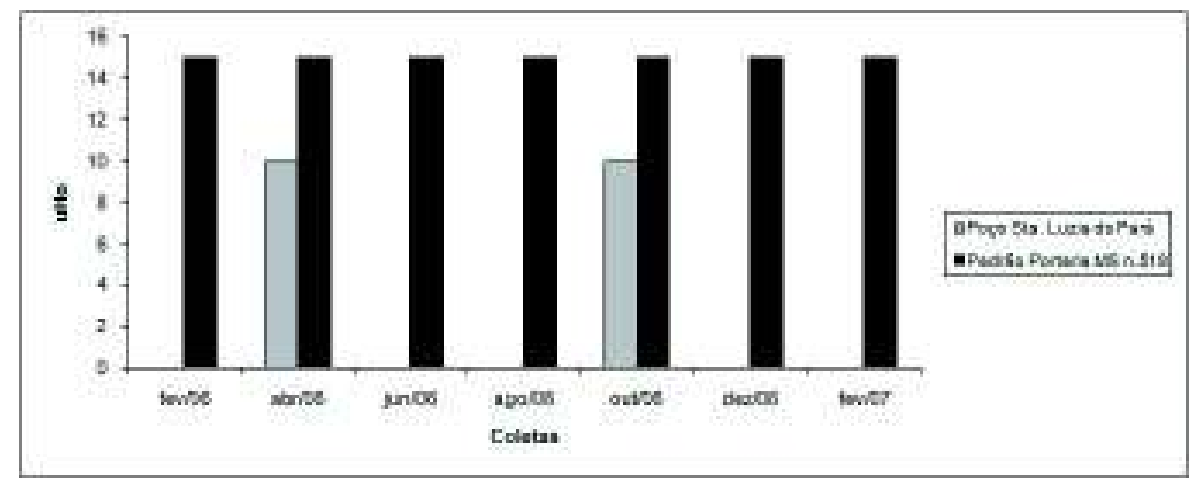

Figura 15 - Valores de cor aparente nos poços tubulares de Santa Luzia do Pará.

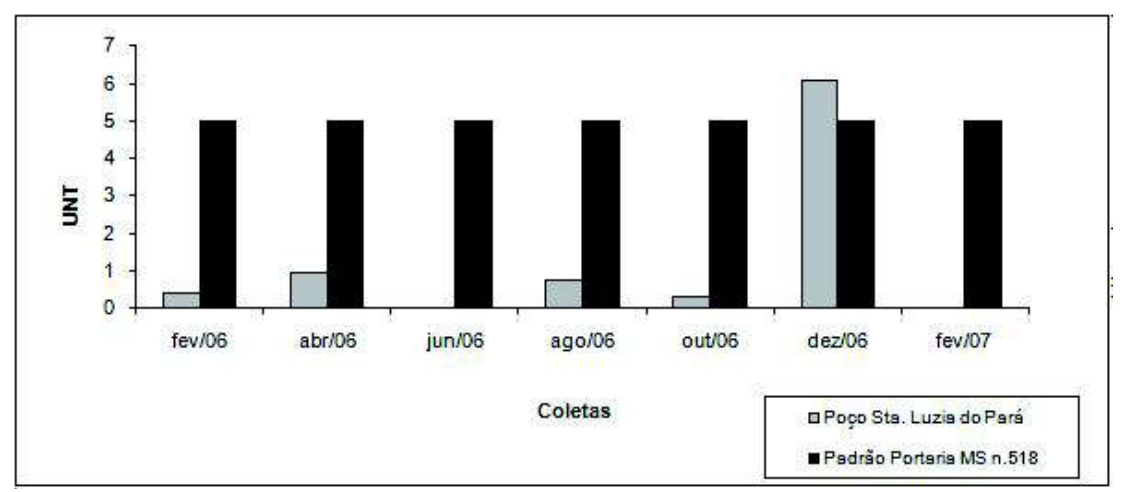

Figura 16 - Valores de turbidez nos poços tubulares de Santa Luzia do Pará.

A Figura 17 apresenta os valores de ferro dissolvido do manancial público de Santa Luzia do Pará. As análises revelaram que em junho/2006 (0,4 mg/L)q, o valor obtido não atendeu ao padrão estabelecido pela Portaria MS. n. $518(0,3 \mathrm{mg} / \mathrm{L})$.

Em relação aos valores de coliformes termotolerantes (Figura 18), o ponto de captação de água de Santa Luzia do Pará não atendeu ao padrão microbiológico de potabilidade do Ministério da Saúde, que exige a ausência de bactérias coliformes em $100 \mathrm{~mL}$ de amostra. Porém, análises detalhadas e com maior periodicidade são imprescindíveis para classificar definitivamente o manancial público. 


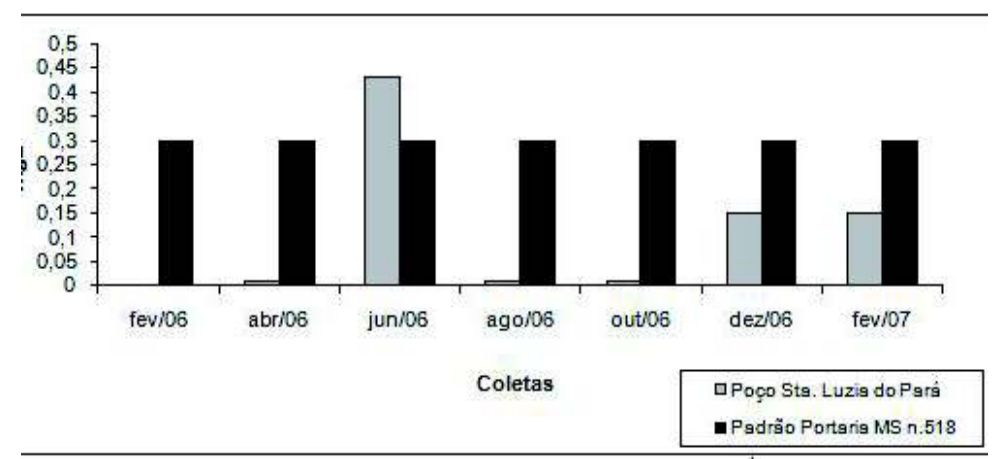

Figura 17 - Valores de ferro dissolvido nos poços tubulares de Santa Luzia do Pará.

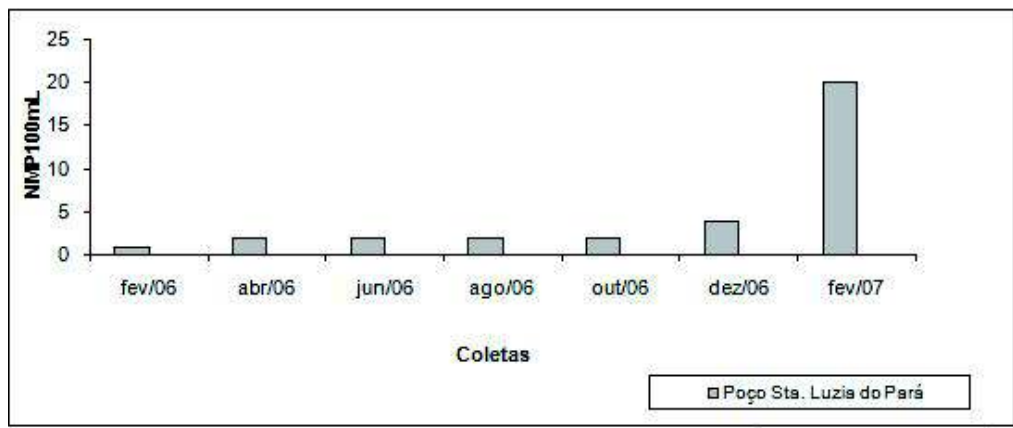

Figura 18 - Valores de coliformes termotolerantes nos poços tubulares de Santa Luzia do Pará.

A amônia livre (Figura 19) atendeu ao padrão estabelecido pela legislação, tendo em vista que o percentual máximo de amônia livre (NH3) permitido pelo Ministério da Saúde é 1,5 mg/L.

Os valores de nitrito e fosfato (Figuras 20 e 21 ) tenderam a zero e os valores de nitrato (Figura 22) revelaram-se dentro do padrão de potabilidade da Portaria MS n. 518 (10 mg/L). O valor mínimo foi $0,19 \mathrm{mg} / \mathrm{L}$, obtido no período de abril/2006.

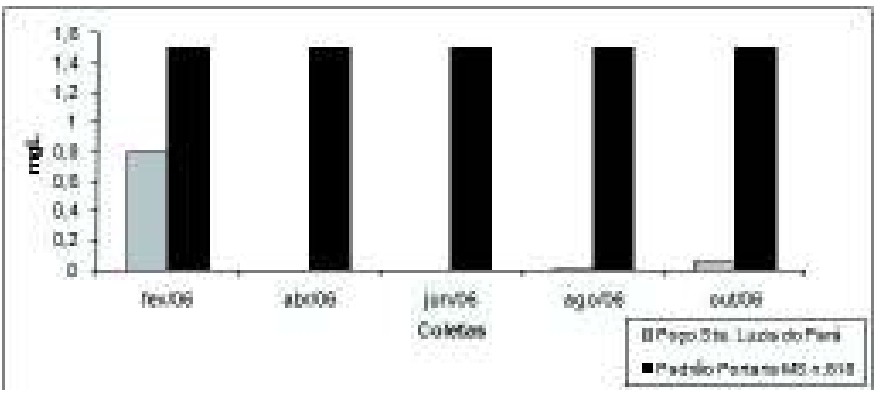

Figura 19 - Valores de amônia livre nos poços tubulares de Santa Luzia do Pará.

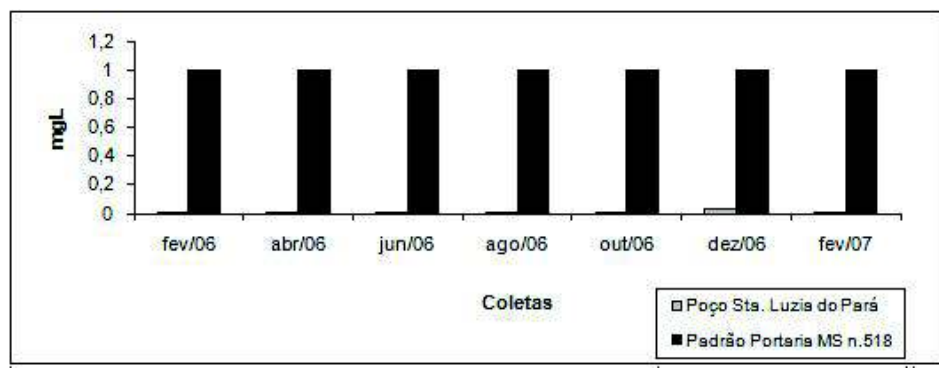

Figura 20 - Valores de nitrito nos poços tubulares de Santa Luzia do Pará. 


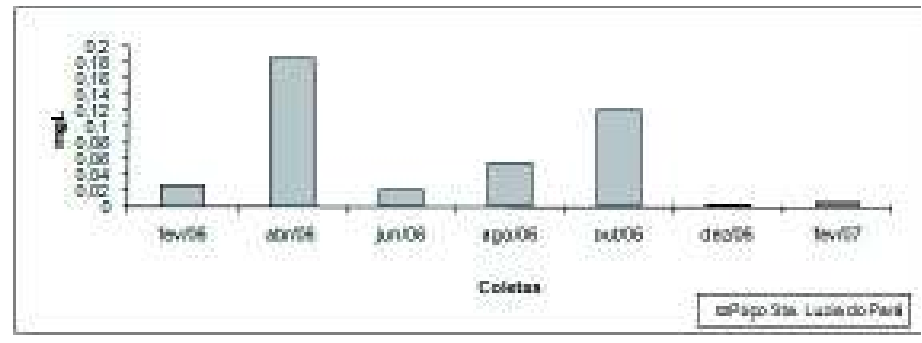

Figura 21 - Valores de fosfato nos poços tubulares de Santa Luzia do Pará.

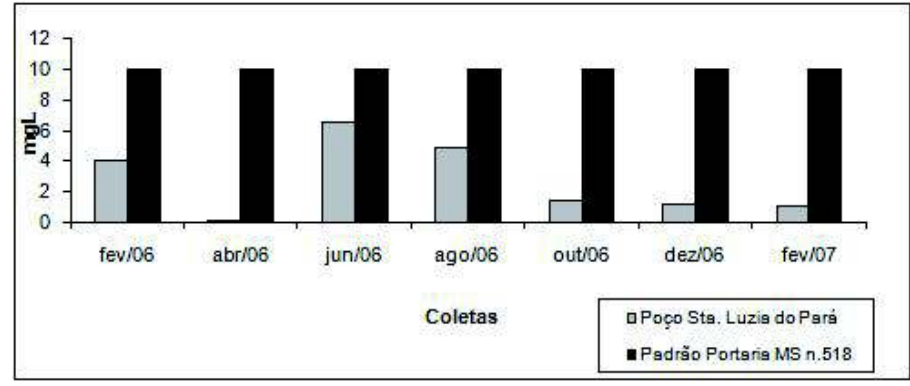

Figura 22 - Valores de nitrato nos poços tubulares de Santa Luzia do Pará.

Assim como no rio Chumucuí, o pH manteve-se com tendência à acidez durante todo o período analisado (Figura 23), seguindo a tendência dos corpos hídricos regionais.

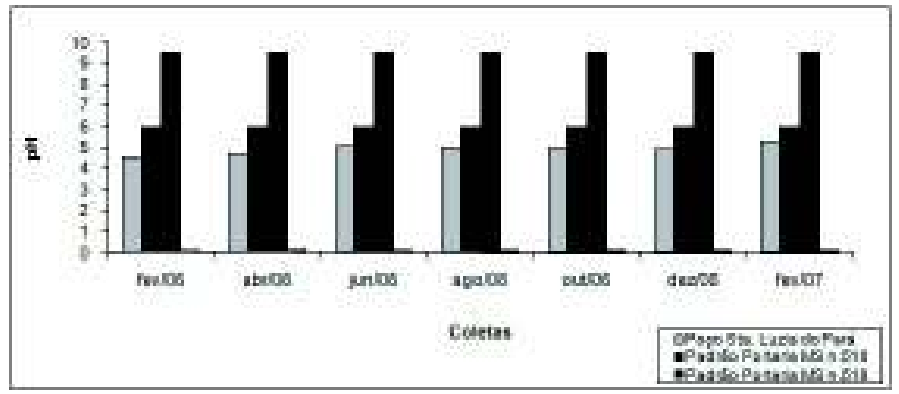

Figura 23 - Valores de pH nos poços tubulares de Santa Luzia do Pará.

A urbanização altera drasticamente a qualidade dos recursos hídricos subterrâneos por meio da super-exploração e da contaminação e poluição. O atual ponto de captação de água de Santa Luzia do Pará situa-se em área de expansão urbana, próximo à sede municipal, a cerca de $1 \mathrm{~km}$ de distância do limite sul da cidade.

As maiores alterações na qualidade da água dizem respeito ao nível de coliformes encontrado no corpo hídrico, acima dos padrões de potabilidade estabelecidos pela legislação brasileira. Portanto, é imprescindível a implementação de um sistema de tratamento de água que obedeça às normas nacionais de saneamento e saúde pública.

Pesquisa realizada por D’águila et al. (2000), na cidade de Nova Iguaçu (Rio Janeiro), corrobora com tal indicativo, posto que foram encontrados coliformes totais, termotolerantes e pseudomonas em $97,7 \%$ dos poços residenciais que não eram submetidos ao tratamento com cloro ativo.

A situação de alteração da qualidade da água devido ao crescimento urbano desordenado não se restringe a casos isolados. Silva e Araújo (2008), analisando a qualidade da água de 120 poços de Feira de Santana (Bahia), identificaram a presença de coliformes termotolerantes em 65,8\% das amostras, bem como desconformidades no padrão de potabilidade relativo ao nitrato $(88,2 \%), \mathrm{pH}$ $(82,8 \%)$, amônia livre $(32,7 \%)$, turbidez $(23,4 \%)$ e cor aparente $(7,5 \%)$. 
Análise da qualidade da água superficial em pontos de amostragem da bacia hidrográfica do rio Caeté

Em relação ao OD, a Figura 24 revela que somente o ponto do rio Curizinho (P-05) não atendeu ao padrão da Resolução n. 357 ( $\geq 5 \mathrm{mg} / \mathrm{LO} 2$ ) e o rio Cereja (P-07), que atravessa a cidade de Bragança, manteve-se no limite do padrão estabelecido pela Resolução. Deve-se considerar que, em geral, um rio tido como limpo apresenta normalmente concentrações entre 8 e $10 \mathrm{mg} / \mathrm{L}$. Porém, essa quantidade pode variar em função da temperatura e da pressão (FARIAS, 2006).

Os valores encontrados podem estar associados às péssimas condições de saneamento básico das sedes municipais, onde os rios citados fazem o papel de receptores de grande carga orgânica oriunda de esgotos domésticos e de outras fontes de poluição difusa (GUIMARÃES et al. 2009a; GUIMARÃES et al. 2009b; PEREIRA et al. No prelo).

Quanto à DBO, a Figura 25 demonstra que todos os pontos de coleta analisados ao longo do rio Caeté atenderam ao limite padrão do CONAMA (2005) $(\leq 5 \mathrm{mg} / \mathrm{L})$, podendo-se destacar o P-05, no município de Santa Luzia do Pará, que apresentou o maior valor (3,7 mg/L) do período.

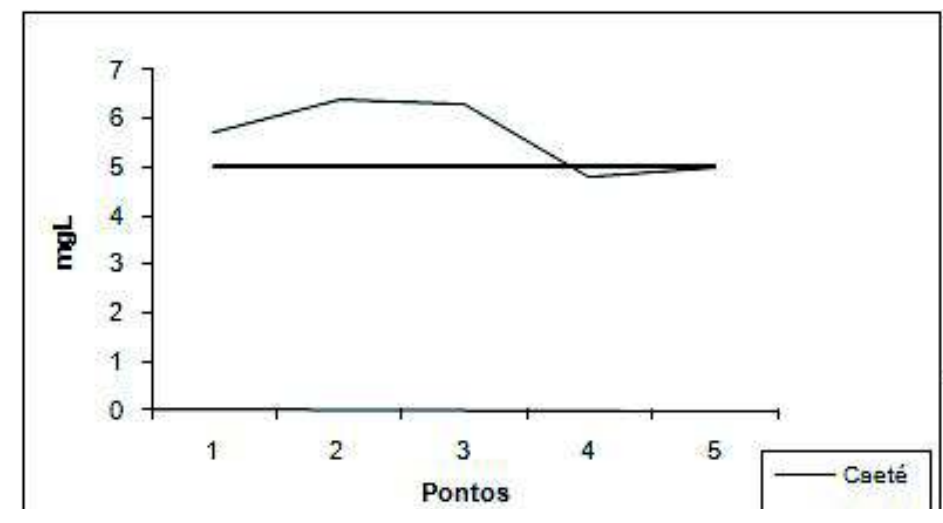

Figura 24 - Valores médios de OD ao longo do rio Caeté.

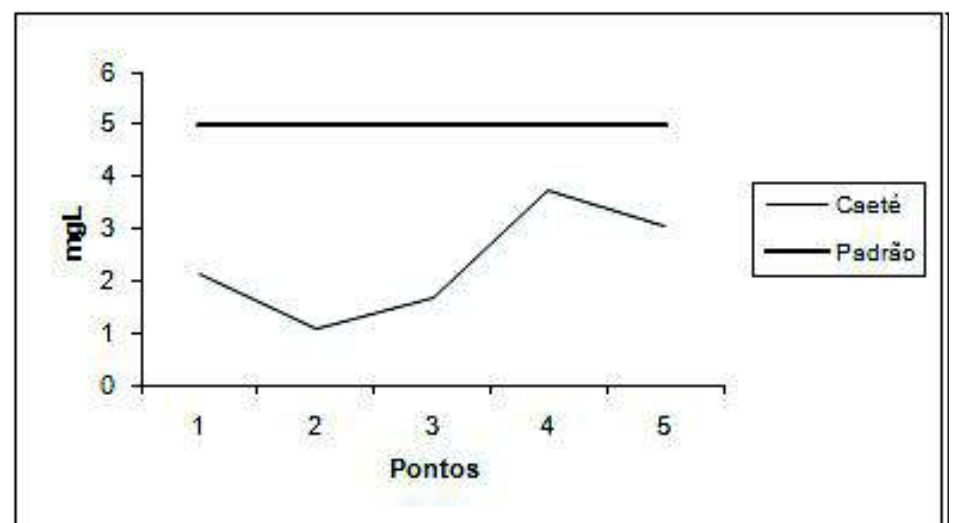

Figura 25 - Valores médios de DBO ao longo do rio Caeté.

Em relação aos valores médios de coliformes termotolerantes, todos os pontos analisados atenderam ao padrão CONAMA (2005), para as águas de Classe 2 (1000 NMP/100mL), porém pode-se observar na Figura 26 que o índice mais baixo foi encontrado no ponto P-05 (58 NMP/100mL), no município de Santa Luzia do Pará, apesar de possuir considerável influência das atividades antrópicas, como o lançamento de esgotos domésticos e de efluentes do matadouro municipal. Acredita-se que as concentrações reveladas demonstram apenas maior intensidade dos usos diversos nos demais pontos de coleta, como atividades pastoris nas nascentes (P-01), atividades de lazer (balneários) nos pontos P-02 (Arraial do Caeté) e P-03 (Tentugal) e concentração de efluentes in natura na cidade de Bragança (P-07). 
Todas as estações ao longo do rio Caeté atenderam ao padrão estabelecido pela legislação para a amônia livre, tendo em vista que o percentual de amônia (NH3), forma tóxica à vida aquática, altera conforme as diferentes faixas de $\mathrm{pH}$. Para os pontos de coleta, os valores de $\mathrm{pH}$ encontrados na água apresentaram-se entre 5 e 6, sendo observado o valor padrão de nitrogênio amoniacal total de $3,7 \mathrm{mg} / \mathrm{LN}$. A Figura 27 ilustra as informações descritas e a Figura 28 detalha o valor do $\mathrm{pH}$ nos pontos de coleta.

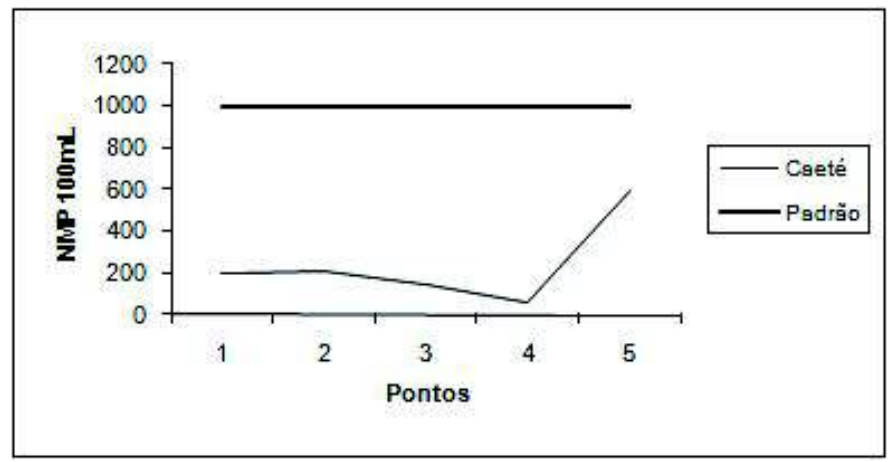

Figura 26 - Valores médios de coliformes termotolerantes ao longo do rio Caeté.

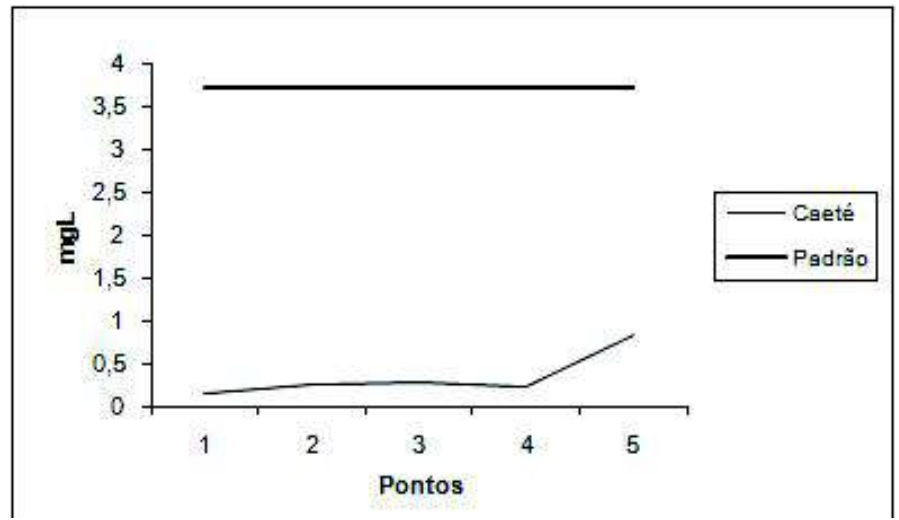

Figura 27 - Valores médios de amônia livre ao longo do rio Caeté.

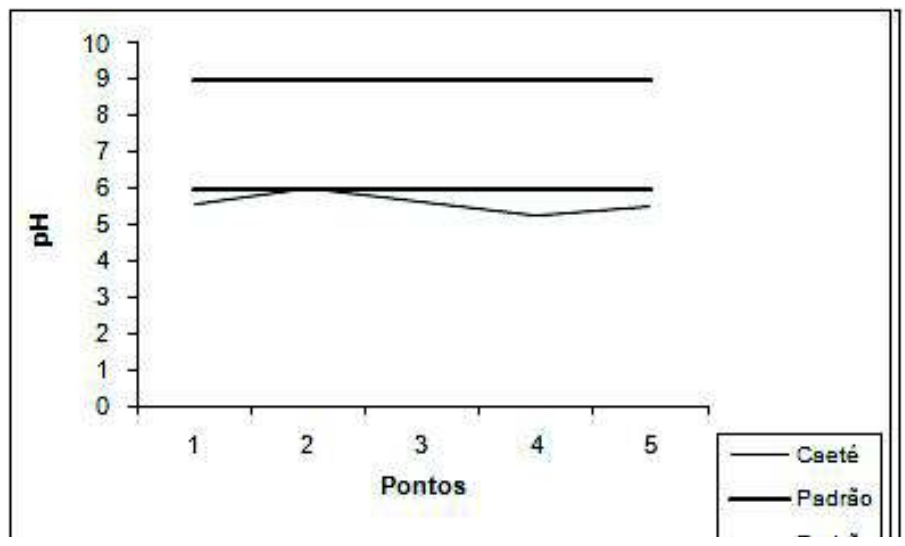

Figura 28 - Valores médios de $\mathrm{pH}$ ao longo do rio Caeté.

Os valores de nitrato e nitrito estão relacionados com a eutrofização dos corpos hídricos e revelaram-se dentro do padrão CONAMA (2005) para as águas de Classe 2: nitrato $<10 \mathrm{mg} / \mathrm{L}$ e nitrito $<1 \mathrm{mg} / \mathrm{L}$. As Figuras 29 e 30 demonstram os valores ponto a ponto. 


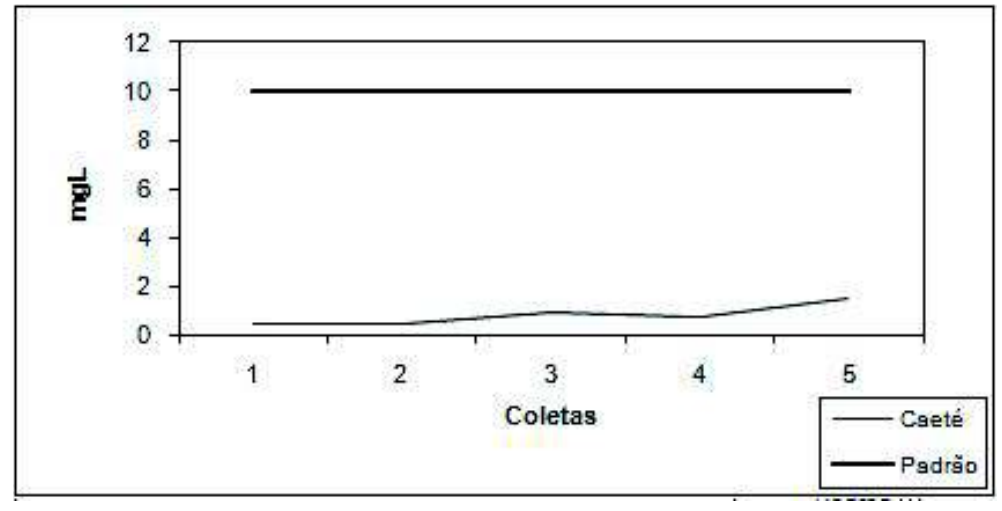

Figura 29 - Valores médios de nitrato ao longo do rio Caeté.

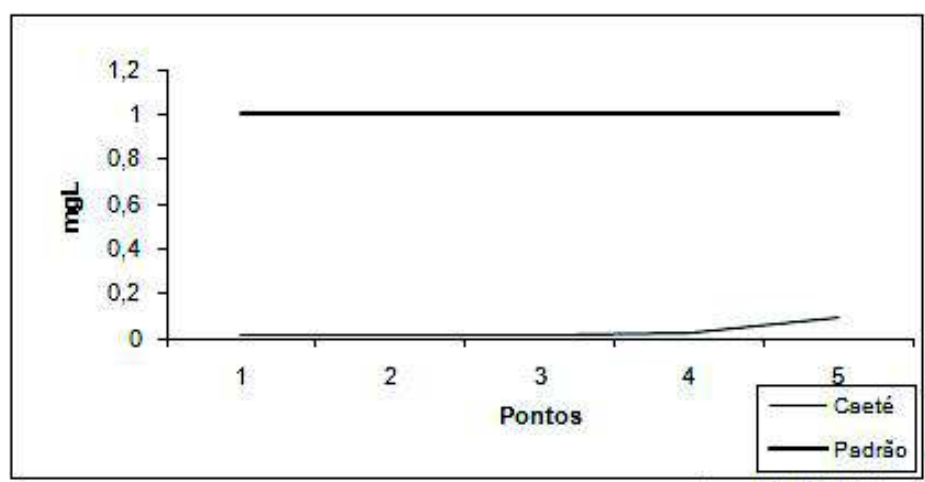

Figura 30 - Valores médios de nitrito ao longo do rio Caeté.

Apesar do fosfato não possuir referência na Resolução n. 357 (CONAMA, 2005), foram registrados valores que tenderam a zero ao longo do Caeté, com exceção do ponto P-07 (rio Cereja) que obteve valor médio mais elevado em relação aos demais $(0,16 \mathrm{mg} / \mathrm{L})$. A Figura 31 ilustra as informações descritas.

Os teores de clorofila-a (Figura 32) ao longo do rio Caeté revelaram que os pontos P-02 (Arraial do Caeté, alto curso), P-05 (rio Curizinho, médio curso) e P-07 (rio Cereja, baixo curso) permaneceram com a média acima do valor recomendando pela Resolução n. 357 para as águas de classe 2. Tais resultados refletem a utilização inapropriada dos corpos hídricos, com balneários às margens do Caeté sem estrutura sanitária e centros urbanos com saneamento básico precário.

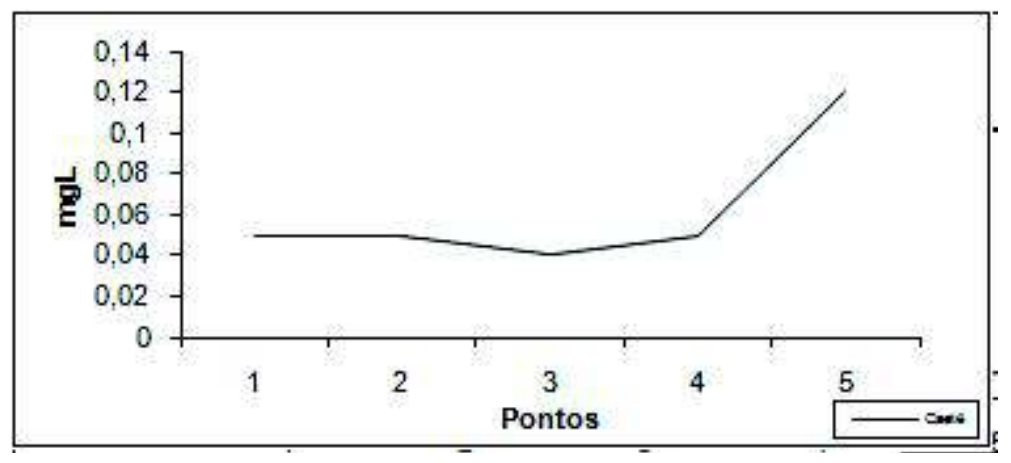

Figura 31 - Valores médios de fosfato ao longo do rio Caeté.

Análises da qualidade da água realizadas por CPRM (1998a) durante o período seco, nos igarapés Caixa d'Água (água doce) e Cereja (água doce) e no rio Caeté (água salobra) na cidade de Bragança, avaliaram os elementos $\mathrm{pH}, \mathrm{OD}, \mathrm{DBO}$, cor aparente, turbidez, série de nitrogênios (amônia livre, nitrato e nitrito), fosfato, ferro dissolvido e coliformes termotolerantes. As análises revelaram que os parâmetros cor, turbidez, série de nitrogênios e fosfato encontraram-se dentro dos padrões estabelecidos pela Resolução n. 357 para as águas doces e estuarinas de classe 2 . 


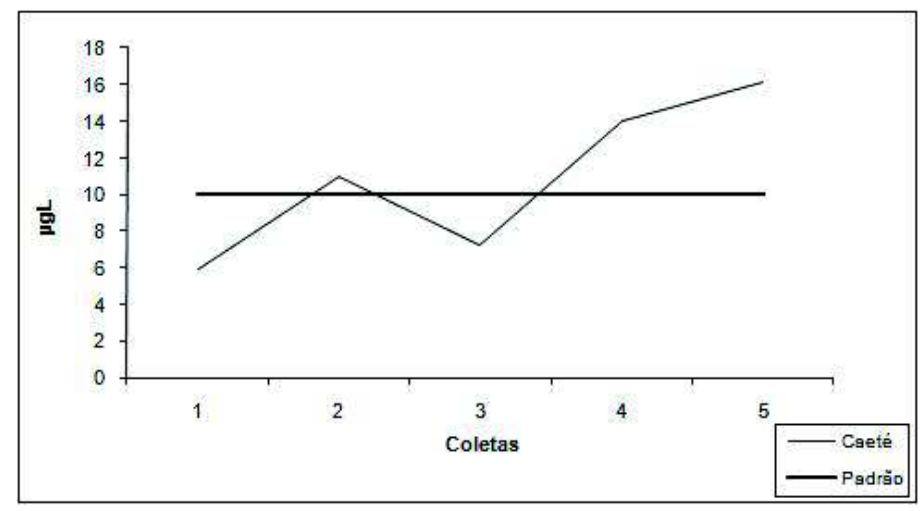

Figura 32 - Valores médios de clorofila-a ao longo do rio Caeté.

Todavia, dados publicados pela CPRM (1998a) constataram que todas as amostras têm tendência à acidez, a concentração de OD no rio Cereja esteve abaixo do valor mínimo estabelecido pela legislação, com 2,0 mg/L O2; o valor de DBO no igarapé Caixa d'Água mostrou-se acima de $5 \mathrm{mg} /$ LO2, com 7,0 mg/LO2; a concentração de ferro esteve acima do padrão CONAMA (2005) para as águas doces e salobras $(0,3 \mathrm{mg} / \mathrm{L})$ nos três pontos, em especial no rio Caeté com concentrações de $5,1 \mathrm{mg} / \mathrm{L}$; e os coliformes termotolerantes estiveram dentro da concentração máxima recomendada pela legislação somente no rio Caeté.

CPRM (1998b) realizou análises da qualidade da água superficial e subterrânea em nove pontos da Bacia Hidrográfica do Rio Tracuateua, que encontra-se situado no limite oeste da bacia do Caeté, durante o período chuvoso, e registrou resultados semelhantes aos encontrados na bacia do rio Caeté: cor de $100 \mathrm{Pt} / \mathrm{Co}$ no rio Tracuateua que atravessa a sede municipal, enquanto o limite máximo recomendado pela Resolução n. 357 é de 75 Pt/Co; pH ácido com valores entre 5 e 6; OD ligeiramente abaixo do padrão CONAMA (2005), com concentrações de 4,7 mg/LO2 no rio Tracuateua; DBO 8 mg/LO2, acima do padrão da Resolução n. 357 ( $\leq 5 \mathrm{mg} / \mathrm{LO} 2)$; e ferro dissolvido que esteve ligeiramente acima do nível máximo recomendado pela legislação brasileira, $0,4 \mathrm{mg} / \mathrm{L}$.

Pereira et al. (In Press) também relacionam dados físico-químicos e microbiológicos, no rio Caeté, especificamente no centro urbano do município de Bragança. Os resultados mostraram que as condições climatológicas, hidrodinâmicas e a falta de saneamento básico interferem na qualidade da água do Caeté, no setor estudado, principalmente no período seco quando os esgotos lançados estão mais concentrados (em decorrência da falta de chuva) tornando, consequentemente, as águas mais eutróficas e com elevadas concentrações de clorofila-a e coliformes termotolerantes.

Em linhas gerais, pode-se considerar que os resultados obtidos pela CPRM (Companhia de Recursos Minerais), assim como por Pereira et al. (2009), Guimarães et al. (2009a) e Guimarães et al. (2009b) revelaram valores semelhantes aos resultados obtidos durante a presente pesquisa, demonstrando que vários indicadores potenciais de poluição se conservam acima dos padrões estabelecidos pela legislação brasileira.

\section{CONSIDERAÇÕES FINAIS}

Conclui-se que desde o alto Caeté até o seu baixo curso, os recursos hídricos estão sendo degradados pela falta de infraestrutura de saneamento básico e pelo manejo inadequado dos recursos naturais, associados à incipiente conscientização da sociedade no que diz respeito à preservação do meio ambiente.

As análises da qualidade da água realizadas nos mananciais públicos, nos igarapés e no rio Caeté revelaram que os pontos de captação de água encontram-se em situação de risco, uma vez que vários parâmetros permaneceram fora dos padrões da legislação brasileira, em destaque os coliformes termotolerantes, que não atenderam ao padrão microbiológico de potabilidade do Minis- 
tério da Saúde (ausência em 100mL), e à acidez hídrica, característica natural das águas da região amazônica que pode, porém, prejudicar a estrutura física dos encanamentos.

Todavia, situação mais grave foi identificada no rio Chumucuí durante o período chuvoso, devido à alteração em vários parâmetros, como: a) turbidez e cor, com valor máximo da cor observado em fevereiro/2007, com $250 \mathrm{uH}$; b) ferro dissolvido, com os valores máximos encontrados em junho/2006 (1,6 mg/L) e c) clorofila-a, com altos teores encontrados nos meses de abril/2006 $(31,8 \mu \mathrm{g} / \mathrm{L})$ e junho/2006 (34,2 $\mu \mathrm{g} / \mathrm{L})$.

Em relação à qualidade ambiental do rio Caeté e seus afluentes, somente o rio Curizinho (médio curso) não atendeu ao padrão da Resolução CONAMA n. 357 para as águas de Classe 2 em relação ao OD e as análises de clorofila-a revelaram que o rio Caeté (alto curso), o rio Curizinho (médio curso) e o rio Cereja (baixo curso) permaneceram com a média acima do valor recomendando pela legislação brasileira. Tais resultados refletem a utilização inapropriada dos corpos hídricos, com balneários às margens do Caeté sem estrutura sanitária e centros urbanos com saneamento básico precário.

Em vista do exposto, são indispensáveis: i) a destinação final adequada dos efluentes de origem domiciliar, hospitalar e do matadouro de Santa Luzia do Pará, com a construção de um sistema de esgotamento sanitário nas cidades de Bragança e Santa Luzia do Pará; ii) a construção de uma ETA em Santa Luzia do Pará; iii) a reforma e ampliação da ETA de Bragança; iv) a preservação da qualidade ambiental dos mananciais, evitando os usos múltiplos dos pontos de captação de água e v) ações de melhoria hídrica para o rio Caeté e afluentes, com a preservação da mata ciliar e a retirada de atividades degradantes das margens dos rios e igarapés.

Contudo, tais ações são pouco eficazes se não existirem políticas de conscientização da população, como ações de educação ambiental realizadas nas instituições públicas e particulares, nos vários níveis educacionais e nas associações comunitárias e empresariais.

As políticas públicas só serão efetivadas se houver um plano integrado de ações para a bacia do Caeté e, mais que isso, para toda a Região Amazônica, envolvendo as várias esferas sociais. Pensar um planejamento integrado para o uso dos recursos hídricos da Amazônia é modificar os índices de desenvolvimento social, criando políticas concretas para o desenvolvimento econômico da região.

Nesse contexto, as políticas direcionadas à gestão de bacias hidrográficas, podendo-se destacar a criação de comitês de bacia e a construção participativa dos Planos Diretores Municipais, revelam-se imprescindíveis para o ordenamento do uso dos recursos hídricos da Região Amazônica, em especial a utilização racional da água.

Finalmente, sabe-se que o ato de diagnosticar a qualidade ambiental, apresenta-se como uma ferramenta fundamental para a viabilização do planejamento regional e do desenvolvimento econômico e social da região. Assim, este estudo pretendeu contribuir para o planejamento regional da Amazônia, entendendo que a sociedade é parte integrante do meio em que vive.

\section{AGRADECIMENTOS}

Os autores agradecem ao Conselho Nacional de Desenvolvimento Científico e Tecnológico (CNPq) pelo financiamento da pesquisa, com os recursos do Projeto "Análise e Monitoramento das Condições Ambientais da Bacia Hidrográfica do Rio Caeté, NE do Pará: Ferramentas para Ação Educativa e Desenvolvimento Sustentável das Comunidades Ribeirinhas" (CNPq CT-Agro Processo n. 552760/2005-6) e do Projeto "Análise Integrada dos Aspectos Sócioambientais de uma Bacia Hidrográfica da Região Amazônica” (CNPq Universal Processo n 471985/2004-0). 


\section{REFERÊNCIA BIBLIOGRÁFICA}

AB'SABER, A. N. Amazônia: do discurso à práxis. São Paulo: Edusp, 2004.

APHA (American Public Health Association); AWWA (American Water Works Association); WEF (Water Environmental Federation). Standard methods for the examinations of water and wasterwater. Washington, 1998.

BAENA, A. R. C.; FALESI, I. C.; DUTRA, S. Características físico-químicas do solo em diferentes agroecossistemas na Região Bragantina do Nordeste Paraense. Belém: EMBRAPAAmazônia Oriental, 1998.

BECKER, K. Undoing myths: the Amazon - an urbanized forest. In: CLUSENER-GODT, M.; SACHS, I. Brazilian perspectives on sustainable development for the Amazon region. Paris: Unesco, 1995.

BECKER, K. A especificidade do urbano na amazônia (Mímeo). Brasília: Sec. de Coordenação da Amazônia, 1998.

BECKER, K. Amazônia: geopolítica na virada do III milênio. Rio de Janeiro: Garamond, 2004.

BRASIL. Ministério das Minas e Energia. Projeto Radambrasil. Levantamento de recursos naturais. v. 3, folha SA. 23, São Luís e parte da folha SA 24 Fortaleza. Rio de Janeiro, 1973. Escala 1: 250.000.

BRASIL. Ministério das Minas e Energia. Decreto n. 76.872, de 22 de dezembro de 1975. Regulamenta a Lei n. 6.050, de 24 de maio de 1974, que dispõe sobre a fluoretação da água em sistemas públicos de abastecimento. Diário Oficial da União: República Federativa do Brasil: Poder Legislativo, Brasília, DF, 22 de dezembro de 1975. Disponível em: <http://www.nesp.unb.br/saude bucalaids/decreto76842_22_12_75. pdf.>. Acesso em: jul. 2008.

BRASIL. Ministério das Minas e Energia. Ministério da Saúde. Estabelece os procedimentos e responsabilidades relativos ao controle e vigilância da qualidade da água para consumo humano e seu padrão de potabilidade, e dá outras providências. Portaria MS n. 518, de 25 de março de 2004. Disponível em: $<$ http://72.14.20 5.104/search?q=cache:WzscMnAer2QJ:portal.saude.gov.br/ portal/arquivos/pdf/portaria_518_2004.pdf + portaria $+\mathrm{ms}+518 \& \mathrm{hl}=\mathrm{pt}-\mathrm{BR} \& \mathrm{ct}=\mathrm{clnk} \& \mathrm{~cd}=1 \& \mathrm{gl}=\mathrm{br} \& \mathrm{client}=$ firefox-a $>$. Acesso em: jun. 2008.

BRASIL. Ministério das Minas e Energia. Ministério da Saúde. Manual de saneamento. Brasília, 2006.

CETESB (Companhia de Tecnologia de Saneamento Ambiental). Variáveis de qualidade das águas. Disponível em: <http.://www.cetesb.sp.gov.br/água/rios/variáveis>. Acesso em: jul. 2007.

CONAMA (Conselho Nacional do Meio Ambiente). Dispõe sobre a classificação dos corpos de água e diretrizes ambientais para o seu enquadramento, bem como estabelece as condições e padrões de lançamento de efluentes, e dá outras providências. Resolução CONAMA nº. 357, de 17 de março de 2005. Diário Oficial da União: República Federativa do Brasil: Poder Legislativo, DF, 17 mar. Disponível em: <http://planeta. terra.com.br/educacao/ kenya/legis/ resolconama 001.htm>. Acesso em: mar. 2005.

CORDEIRO, J. S.; CAMPOS, J. R.. O impacto ambiental provocado pela indústria da água. Acta Geneticae Medicae et Gemellologiae, São Paulo, v. 10, n. 50, p. 52-57, 1999.

COSANPA (Companhia de Saneamento do Pará). Processo de tratamento de nossa água de captação fluvial. Disponível em: http://www.cosanpa.pa.gov.br/processodetratamento.htm>. Acesso em: jun. 2007.

CPRM (Companhia de Recursos Minerais). Diagnóstico dos recursos hídricos da cidade de Bragança. Belém, 1998a.

CPRM (Companhia de Recursos Minerais). Diagnóstico dos recursos hídricos da cidade de Tracuateua. Belém, 1998b.

D'ÁGUILA, P. S. et al. Avaliação da qualidade de água para abastecimento público do município de Nova Iguaçu. Cad. Saúde Pública, Rio de Janeiro, v. 16, n. 3, p. 791-798, jul-set, 2000.

FARIAS, M. S. S. Monitoramento da qualidade da água na bacia hidrográfica do rio Cabelo. 2006. Tese (Doutorado em Engenharia Agrícola), Pós-Graduação em Engenharia Agrícola, Universidade Federal de Campina Grande, Campina Grande, 2006.

FERREIRA, W. A. F.; BOTELHO, S. M. Propriedade de um Gleissolo Háplico Sódico típico a moderado, textura muito argilosa de Várzea do rio Caeté, no município de Bragança-PA, sob inundação. Belém: EMBRAPA Amazônia Oriental, 1999. 
FERREIRA, M. S. G.; OLIVEIRA, L. C. Potencial produtivo e implicações para o manejo de capoeiras em áreas de agricultura tradicional do Nordeste Paraense. Belém: EMBRAPA Amazônia Oriental, 2001.

FEZA, J. P. Desnível pode transformar flúor em "vilão". Oscilação da substância preventiva da cárie adicionada na água que chega à população motiva FOB/USP a desenvolver heterocontrole da fluoretação. Jornal da USP, São Paulo, ano XIX, n.691, jun. 2004. Disponível em: <http://www .usp.br/jorusp/arquivo/2004/ jusp691/pag05.htm>. Acesso em: jun. 2008.

GORAYEB, A.; LOMBARDO, M. A.; PEREIRA, L. C. C. Condições ambientais em áreas urbanas da bacia hidrográfica do rio Caeté - Amazônia Oriental - Brasil. Revista da Gestão Costeira Integrada, Itajaí, v. 9, n. 2, p. 59-70, 2009.

GORAYEB, A. ANálise integrada da paisagem na bacia hidrográfica do rio Caeté - Amazônia Oriental - Brasil. Tese (Doutorado em Geografia), Programa de Pós-Graduação em Geografia, Universidade Estadual de São Paulo, Rio Claro, 2008.

GRASSHOFF, K.; EMRHARDT, M.; KREMLING, K. Methods of seawater analysis. New York: Verlag Chemie, 1983.

GUIMARÃES, D. O. et al. Aspectos Socioeconômicos e ambientais das comunidades rurais da bacia hidrográfica do rio Caeté (Pará - Brasil). Revista da Gestão Costeira Integrada, Itajaí, v. 9, n. 2, p. 71-84, 2009a.

GUIMARÃES, D. O. et al. Effects of the urban influence on the Cereja River and Caeté Estuary (Amazon littoral, Brazil). Journal of Coastal Research, v. SI56, n.2, p.1219-1223, 2009 b.

HORBE, A. M. C. et al. Contribuição à hidroquímica de drenagens no município de Manaus - AM. Acta Amazônica, Manaus, v. 35, n. 2, p. 119-124, 2005.

IBGE (Instituto Brasileiro de Geografia e Estatística). Cidades @. 2000. Disponível em: <http.:// www.ibge. gov.br/ cidadesat/ topwindow. htm?0>. Acesso em: fev. 2004.

LOPES, O. M. N.; RODRIGUES, T. E.; OLIVEIRA JÚNIOR, R. C. Determinação de perdas de solo, água e nutrientes em Latossolo Amarelo, textura argilosa do Nordeste Paraense. Belém: EMBRAPA Amazônia Oriental, 1999.

LOUREIRO, V. R. Desenvolvimento, cultura, meio ambiente. In: SIMÕES, M. S. (Org.). Cultura e biodiversidade: entre o rio e a floresta. Belém: UFPA, 2001.

LUCAS, A. A. T. Impacto na irrigação da bacia hidrográfica do Ribeirão dos Marins. 2007. Tese (Doutorado em Ecologia Aplicada), Escola Superior de Agricultura Luiz de Queiroz, Universidade de São Paulo, Piracicaba, 2007.

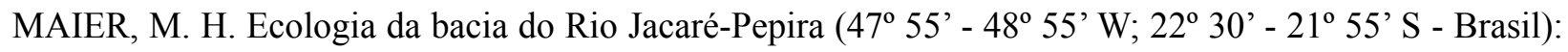
qualidade da água do rio principal. Ciência \& Cultura, Campinas, v. 39, n. 2, p. 164-185, 1987.

MIRANDA et al. Qualidade dos recursos hídricos da Amazônia - Rio Tapajós: avaliação de caso em relação aos elementos químicos e parâmetros físico-químicos. Revista Ambiente e Água, Taubaté, v. 4, n. 2, p. 75-92, 2009.

OLIVEIRA JUNIOR, R. C et al. Zoneamento agroecológico do município de Tracuateua, estado do Pará. Belém: EMBRAPA Amazônia Oriental, 1999.

PARÁ. Secretaria Executiva de Ciência, Tecnologia e Meio Ambiente. Macrozoneamento ecológicoeconômico do estado do Pará/2004: proposta para discussão. Belém, 2004.

PEREIRA, L. C. C.; MONTEIRO, M. C.; GUIMARÃES, D. de O.; J. B. M.; COSTA, R. M. da. Seasonal effects of wastewater on Caeté Estuary water quality. Anais da Academia Brasileira de Ciências. No prelo. ROSÁRIO, U. Saga do Caeté: folclore, história, etnografia e jornalismo na cultura amazônica da Marujada, Zona Bragantina, Pará. Belém: CEJUP, 2000.

SANTOS, P. L. et al. Zoneamento Agroecológico do município de Augusto Corrêa, estado do Pará. Belém: EMBRAPA Amazônia Oriental, 1999.

SANTOS, I. N. et al. Influência de um aterro sanitário e de efluentes domésticos nas águas superficiais do Rio Tarumã e afluentes - AM. Acta Amazônica, Manaus, v. 36, n. 2, p. 229-236, 2006.

SILVA, I. R.; PEREIRA, L. C. C.; COSTA, R. M. Exploração de argila em Fazendinha e os Impactos Socioambientais (Amazônia, Brasil). Revista da Gestão Costeira Integrada, Itajaí, v. 9, n. 2, p. 85-90, 2009. 
SILVA, A. E. P. et al. Influência da precipitação da qualidade da água do Rio Purus. Acta Amazônica, Manaus, v. 38, n. 4, p. 733-742, 2008.

SILVA, R. C.A; ARAÚJO, T. M. Qualidade da água do manancial subterrâneo em áreas urbanas de Feira de Santana (BA). Disponível em: < http://www.scielo.br/pdf/csc/v8n4 /a23v8n4. pdf. Acesso em: jul. 2008.

SOUZA FILHO, P.W.M; EL-ROBRINI, M. Morfologia, processos de sedimentação e litofácies dos ambientes morfo-sedimentares da Planície Costeira Bragantina - Nordeste do Pará (Brasil). Geonomos, Belo Horizonte, v. 4, n. 2, p. 1-16, 1996.

SOUZA FILHO, P.W.M; EL-ROBRINI, A Planície Costeira Bragantina (NE do Pará): influência das variações do nível do mar na morfoestratigrafia costeira durante o holoceno. Dissertação (Mestrado em Geologia e Geoquímica), Pós-Graduação em Geologia e Geoquímica, Universidade Federal do Pará, Belém, 1995.

STRICKLAND, J. D. H; PARSONS, T. R. A pratical handbook of seawater analysis. Journal of Fisheries Research Board of Canada, Ottawa, 310p, 1972.

VASCONCELLOS, M. C. C. Prevalência de cárie dentária em escolares de 7 a 12 anos de idade, na cidade de Araraquara, SP (Brasil), 1979. Revista de Saúde Pública, São Paulo, v.16, n.6, dez. 1982. Disponível em: < http://www.scielo.br/scielo.php?pid=S0034-89101982000600002\&script $=$ sci_arttext $>$. Acesso em: jun. 2008.

Trabalho enviado em janeiro de 2010

Trabalho aceito em abril de 2010 